\title{
Testing the effectiveness of an acoustic deterrent for gray whales along the Oregon coast
}

\section{Final Scientific Report}

December 2012

U.S. Department of Energy

Report No: DOE/DE-EE0002660

Barbara Lagerquist, Martha Winsor, and Bruce Mate

Oregon State University Marine Mammal Institute

This project was funded by the U.S. Department of Energy, through an award to Pacific Energy Ventures LLC (Award Number DE-EE0002660). This work was also supported in part by the Oregon Wave Energy Trust, the Northwest National Marine Renewable Energy Center, and Oregon State University's Marine Mammal Endowment. The U.S. Bureau of Land Management's Yaquina Head Outstanding Natural Area provided logistical support and access to the deck in front of Yaquina Head Lighthouse for project observations. 


\section{Table of Contents}

EXECUTIVE SUMMARYY FIGURES

\section{List of Figures}

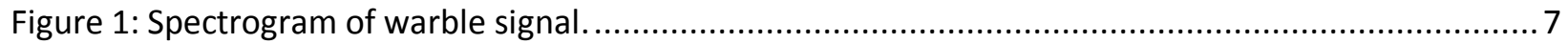

Figure 2: Plot of mean received level of deterrent sound with increasing distance from source .............. 8

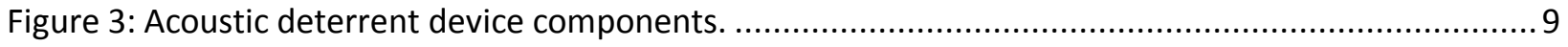

Figure 4: Waterproof housings containing Airmar signal generator and batteries mounted on Lander

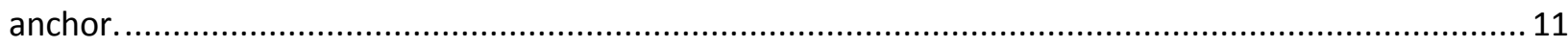

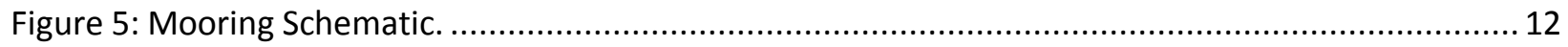

Figure 6: Number of whales per hour located during scan surveys................................................ 15

Figure 7: Gray whale locations obtained during scan sampling and focal follow surveys. ..................... 16

Figure 8: Locations of southbound gray whales obtained during focal follow sampling....................... 17

Figure 9: Locations of northbound gray whales obtained during focal follow sampling. ...................... 18

Figure 10: Gray whale locations for experimental versus control periods........................................ 20

\section{List of Tables}

Table 1: Frequency and cumulative count of locations located within specified distances to the deterrent mooring location. 


\section{Executive Summary}

This study was conducted to determine whether a low-powered sound source could be effective at deterring gray whales from areas that may prove harmful to them. With increased interest in the development of marine renewal energy along the Oregon coast the concern that such development may pose a collision or entanglement risk for gray whales. A successful acoustic deterrent could act as a mitigation tool to prevent harm to whales from such risks.

In this study, an acoustic device was moored on the seafloor in the pathway of migrating gray whales off Yaquina Head on the central Oregon coast. Shore-based observers tracked whales with a theodolite (surveyor's tool) to accurately locate whales as they passed the headland. Individual locations of different whales/whale groups as well as tracklines of the same whale/whale groups were obtained and compared between times with the acoustic device was transmitting and when it was off.

Observations were conducted on $51 \mathrm{~d}$ between January 1 and April 15, 2012. A total of 143 individual whale locations were collected for a total of 243 whales, as well as 57 tracklines for a total of 142 whales. Inclement weather and equipment problems resulted in very small sample sizes, especially during experimental periods, when the device was transmitting. Because of this, the results of this study were inconclusive.

We feel that another season of field testing is warranted to successfully test the effectiveness of the deterrent, but recommend increasing the zone of influence to $3 \mathrm{~km}$ to ensure the collection of adequate sample sizes. Steps have been taken to acquire the necessary federal research permit modification to authorize the increased zone of influence and to modify the acoustic device for the increased power.

With these changes we are confident we will be able to determine whether the deterrent is effective at deflecting gray whales. A successful deterrent device may serve as a valuable mitigation tool to protect gray whales, and other baleen whales, in the event that marine energy development poses a collision or entanglement risk. 


\section{Introduction}

The Oregon coast has been identified as an area with great potential for production of electricity from wave energy and plans are underway to develop several different projects along the Pacific Northwest coast. One such plan, involves the initial deployment of one Ocean Power Technologies' (OPT) test buoy off Reedsport, Oregon to be followed up shortly thereafter with the deployment of an array of 10 OPT buoys. In light of this development, there is a pressing need to begin examining how ocean wave energy development might impact the marine environment, biological communities, and individual species (Boehlert et al. 2008). Very little information currently exists on the environmental effects of this new technology, however numerous reports have identified collision and entanglement as potential risks to marine mammals (Gill 2005, Wilson et al. 2007, Boehlert et al. 2008, Ortega-Ortiz and Lagerquist 2008, Dolman and Simmonds 2010).

Collisions can occur when animals encounter obstacles in their environment and fail to avoid or evade the obstacles. In the case of wave energy technology, these obstacles could include surface structures, submerged structures, and mooring lines/cables holding structures in place. Marine mammals may collide with such structures as they swim through the water column, when they come to the surface to breathe, or as a result of structures being pushed down on them in times of heavy seas (Wilson et al. 2007). As discussed in their 2007 report on collision risks between marine renewable energy devices and mammals, fish and diving birds, the outcomes of collisions are likely to vary, ranging from minor (abrasions) to major injuries (internal trauma, damage to delicate organs), or even mortality (Wilson et al. 2007).

Collision risk will depend on the type and quantity of structures involved and how aware marine mammals are of their presence, which in turn will depend on the "visibility" of the structures, oceanographic conditions, time of day, and the sensory capabilities of the animals as well as their age and behavioral state (Wilson et al. 2007). It is believed that baleen whales may be at more risk than echolocating odontocetes or highly maneuverable pinnipeds, especially in regard to mooring lines/cable that may be harder to detect in the water column than larger structures.

Subsea floats used to maintain mooring lines and cables under maximum tension can minimize the potential for entanglement (U.S. Department of Energy 2012). However, marine mammals may become entangled in mooring lines or cables associated with wave energy devices if such lines are slack or capable of forming loops (Boehlert et al. 2008). Additionally, derelict fishing line or nets may become entangled on mooring lines/cables and may themselves add to the entanglement risk to marine mammals.

The gray whale (Eschrichtius robustus) is the most numerous large cetacean along the nearshore Oregon coast. It is part of the Eastern North Pacific population and is protected under the U.S. Marine Mammal Protection Act, with a minimum population estimate of 18,017 animals (NOAA 2011). The majority of the Eastern North Pacific population spends the summer feeding in the northern Bering, Beaufort, and Chukchi Seas. A small portion of this population, about 200-250 animals, feeds along the west coast of Northern California, Oregon, Washington, British Columbia, and southeast Alaska during the summer 
and fall (Rice and Wolman 1971, Darling 1984, Nerini 1984, Rice et al. 1984, Calambokidis et al. 2002, Newell and Cowles 2006, Calambokidis et al. 2009).

Every year, a significant part of the population of Eastern North Pacific gray whales migrates from their summer feeding grounds towards calving lagoons in Baja California, Mexico and back (Rice and Wolman 1971). Shore-based observations in the late 1970's and early 1980's indicated that southbound whales pass by Yaquina Head on the central Oregon coast between early December and mid-February (Herzing and Mate 1984), with a peak in late December/early January (Herzing and Mate 1984, Mate and Poff 1999). Northbound migration includes two phases; Phase A, consisting of pregnant females, anestrus females, adult males, and juveniles of both sexes (Rice et al. 1984), and Phase B, consisting of cows with calves (Poole1984). Off Oregon, Phase A of northbound migration starts the last week of February and peaks in mid-March, while Phase B begins in late April and peaks in mid-May (Herzing and Mate 1984). Gray whale migration along Oregon is primarily coastal. The average distance from shore for sightings recorded during aerial surveys off the Oregon coast was $9.2 \mathrm{~km}$ and the farthest sighting occurred $23 \mathrm{~km}$ offshore (Green et al. 1995).

The need for more current information on the distribution (distance to shore, travel path) and behavior (travel speed, migration timing) of gray whales migrating along the Oregon coast led to a shore-based observational study of gray whales migrating by Yaquina Head from December 2007-May 2008 (OrtegaOrtiz and Mate, 2008). This work was funded by the Oregon Wave Energy Trust (OWET), a non-profit organization tasked with promoting responsible development of a wave energy industry in the State of Oregon, and was conducted by Oregon State University's Marine Mammal Institute (OSUMMI).

The 2007/2008 study used a theodolite to very accurately track the position and movement of gray whales passing Yaquina Head within $18 \mathrm{~km}$ from shore (Ortega-Ortiz and Mate, 2008). Locations were recorded of all whales seen during scan surveys of the $200^{\circ}$ field of view of the ocean, as well as of individual groups tracked during focal follows. Average distance from shore, median depth of locations, and average speed were all significantly different between southbound and northbound phases of migration. $61 \%$ of all whales and $78 \%$ of mothers and calves passed within 3 nautical miles of shore. Migration paths of tracked whales followed a reasonably consistent depth rather than the shoreline.

These results showed that the migration paths of some gray whales crossed through areas of proposed wave energy development along the Oregon coast. Deployment of structures for wave energy facilities (buoys, cables, mooring systems, etc.) in the migratory path of gray whales raises the possibility of collisions and/or entanglements for these animals (Boehlert et al. 2008). It is desirable, then, to develop appropriate mitigation measures that can be brought into play should such negative effects of wave energy development be realized.

One such mitigation measure is the use of underwater acoustic devices, such as low-powered deterrents, which have been successfully used to protect marine mammals from entanglement in fishing nets (Kraus et al. 1997, Trippel et al. 1999, Gearin et al. 2000, Barlow and Cameron 2003). Sound playback also has a role in non-fisheries related management of marine mammals, such as in the prevention of harm from other human activity (e.g. seismic testing, underwater explosions), or to prevent stranding or other 
accidental death (Deecke 2006). The first use of underwater noise to protect a mysticete from harm was reported by Mobley et al. (1988), when sounds of conspecifics were used to lure a humpback whale out of the Sacramento River in California, thereby preventing the animal from accidental stranding. Since then investigations of behavioral responses to underwater noise have been conducted to decrease the risk of vessel collisions (Deecke 2006). For example, André et al. (1997) played artificial and natural sounds to sperm whales in the Canary Islands to ultimately reduce collisions with high-speed ferries in the area, and Nowacek et al. (2004) tested the response to ship noise, conspecific sounds, and an alert signal to reduce the number of ship strikes involving North Atlantic right whales.

During the winter and spring of 2012 OSUMMI conducted a study, with funding from the Department of Energy, to test the effectiveness of an acoustic deterrent for gray whales. A successful deterrent could be used as a mitigation tool to keep gray whales away from potentially harmful situations, such as might arise with the development of hydrokinetic energy along the Oregon coast. The study's objective was to keep gray whales $500 \mathrm{~m}$ away from the deterrent device. In early January 2011 the acoustic device was moored on the seafloor approximately $5 \mathrm{~km}$ west of Yaquina Head, Oregon, in the path of migrating gray whales. The device transmitted a 1-s 1-3 kHz warble with a source level of $170 \mathrm{~dB}$ re $1 \mu \mathrm{Pa}$ at $1 \mathrm{~m}$ every $20 \mathrm{~s}$ during a 6.2-h experimental period during daylight hours. Shore-based observations, using a theodolite to accurately locate whales, were conducted from January through mid-April, 2012, using similar observation methods as the Ortega-Ortiz and Mate (2008) study.

\section{Methods}

\section{Acoustic deterrent signal characteristics and sound source}

A 1-s, frequency-modulated 1-3 kHz warble was chosen as the deterrent signal, to represent a novel non-natural sound within the presumed hearing range of gray whales (Figure 1). Gray whales have been recorded producing sounds ranging in frequency from 20-10,000 Hz (Cummings et al. 1968, Fish et al. 1974, Norris et al. 1977, Dahlheim et al. 1984, Moore and Ljungblad 1984)., but the dominant frequencies of their sound production range from $20-4,000 \mathrm{~Hz}$. To date there have been no direct measures of hearing for any mysticete (Ketten 2000). It is reasonable, however, to expect they have good auditory sensitivity near the frequencies they emit (Richardson et al. 1995, Ketten 2000). The 1-3 kHz signal in this study was chosen as it is within the dominant frequencies produced by gray whales, but high enough to keep logistical considerations manageable (low frequency sound production requires large projectors and considerable battery power) The warble effect was chosen to represent a novel sound, unlike anything gray whales would have had prior experience with in their environment, and thereby elicit a greater response. 


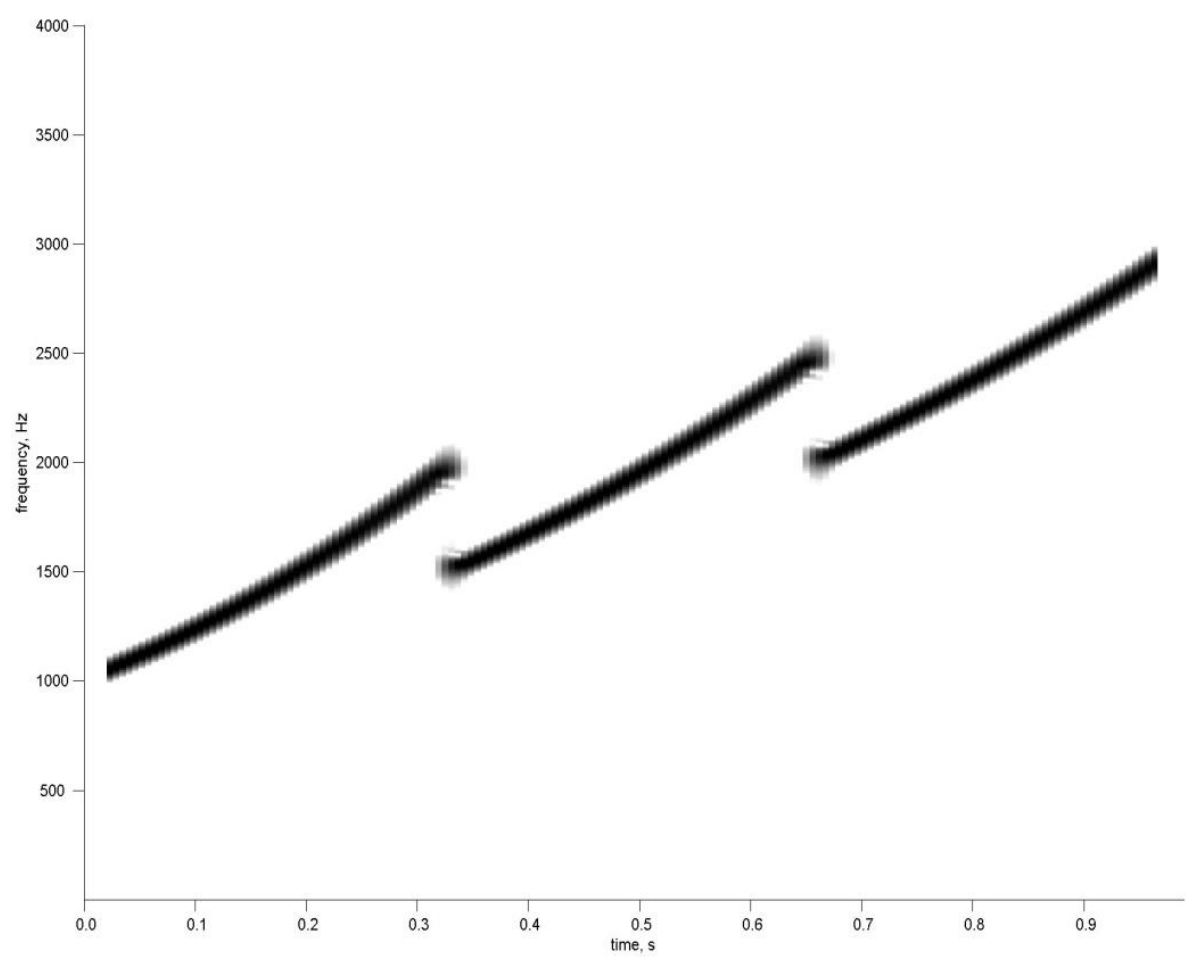

Figure 1: Spectrogram of warble signal being tested in the study as a possible deterrent for gray whales.

Migrating gray whales have been shown to exhibit avoidance responses to playback studies at received levels of $120 \mathrm{~dB}$ or more. In the Malme et al. $(1983,1984)$ studies, migrating gray whales were exposed to sounds associated with petroleum industry activities. Their results showed that approximately $50 \%$ of the whales avoided exposure to continuous sounds (i.e. engine or drilling noise) at received levels of 120 $\mathrm{dB}$ re $1 \mu \mathrm{Pa}$, and 50\% avoided impulses from airguns at received levels of $170 \mathrm{~dB}$ re $1 \mu \mathrm{Pa}$. Another playback study using migrating gray whales was that by Tyack and Clark, to evaluate the impact of Low Frequency Active (LFA) sonar on the animals. This study showed that whales increased their avoidance distance with increased source level when the sound source was moored in the middle of the migration corridor (2009b). Approximately half of the whales in this study avoided exposures of $\sim 140 \mathrm{~dB}$ re $1 \mu \mathrm{Pa}$ (Buck and Tyack 2000).

In this study, a received level of sound of $120 \mathrm{~dB}$ re $1 \mu \mathrm{Pa}$ at $1 \mathrm{~m}$ was hypothesized as the level above which 50 percent of migrating gray whales would exhibit an avoidance response. This was based on the findings of Malme et al. $(1983,1984)$ and consultation with acoustic experts (Chris Clark, Cornell University; Dave Mellinger, Oregon State University; Brandon Southall, Southall Environmental Associates, Inc.; Aaron Thode, Scripps Institute of Oceanography; and Peter Tyack, University of St. Andrews, Scotland). A radius of $500 \mathrm{~m}$ around the sound source was chosen as the desired zone of influence, or the area at which we expected to see an avoidance response by the whales, as this distance would give whales ample opportunity to avoid a wave energy buoy (Ortega-Ortiz and Lagerquist 2008). 
An acoustic propagation model was developed by Küsel et al. (2009) to determine the source level required to produce a received level of $120 \mathrm{~dB}$ at the desired range of $500 \mathrm{~m}$. Sound speed profiles collected in December 2008 and March 2009 at 1, 3, 5, and 10 miles along the Newport Hydrographic Line ( $44^{\circ} 39^{\prime}$ North Latitude) were provided by Bill Peterson (NOAA-NWFSC) and used in the model calculations. Bathymetry used in model calculations was obtained online from the National Geophysical Data Center (NGDC - US Coastal Relief Model Grids). The model was run using a $2 \mathrm{kHz}$ sound with source levels ranging from 160-180 dB. Two suspension depths for the transducer (10 and $25 \mathrm{~m}$ below the ocean surface) and four transects (north, south, east, and west) were tested for each of three proposed mooring locations due west of Yaquina Head, Oregon ( $40 \mathrm{~m}, 45 \mathrm{~m}$, and $50 \mathrm{~m}$ water depth).

Plots of noise levels in $\mathrm{dB}$ as a function of distance from the source and depth were similar between seasons, suspension depths, transects, and mooring locations. Results from model calculations suggested that a source level of $168 \mathrm{~dB}$ would attenuate to a received level of $120 \mathrm{~dB}$ throughout the water column at a distance of $500 \mathrm{~m}$ from the source (Figure 2). A source level of $170 \mathrm{~dB}$ was ultimately chosen to allow for variation in the model results and ensure that a $500 \mathrm{~m}$ zone of influence was achieved.

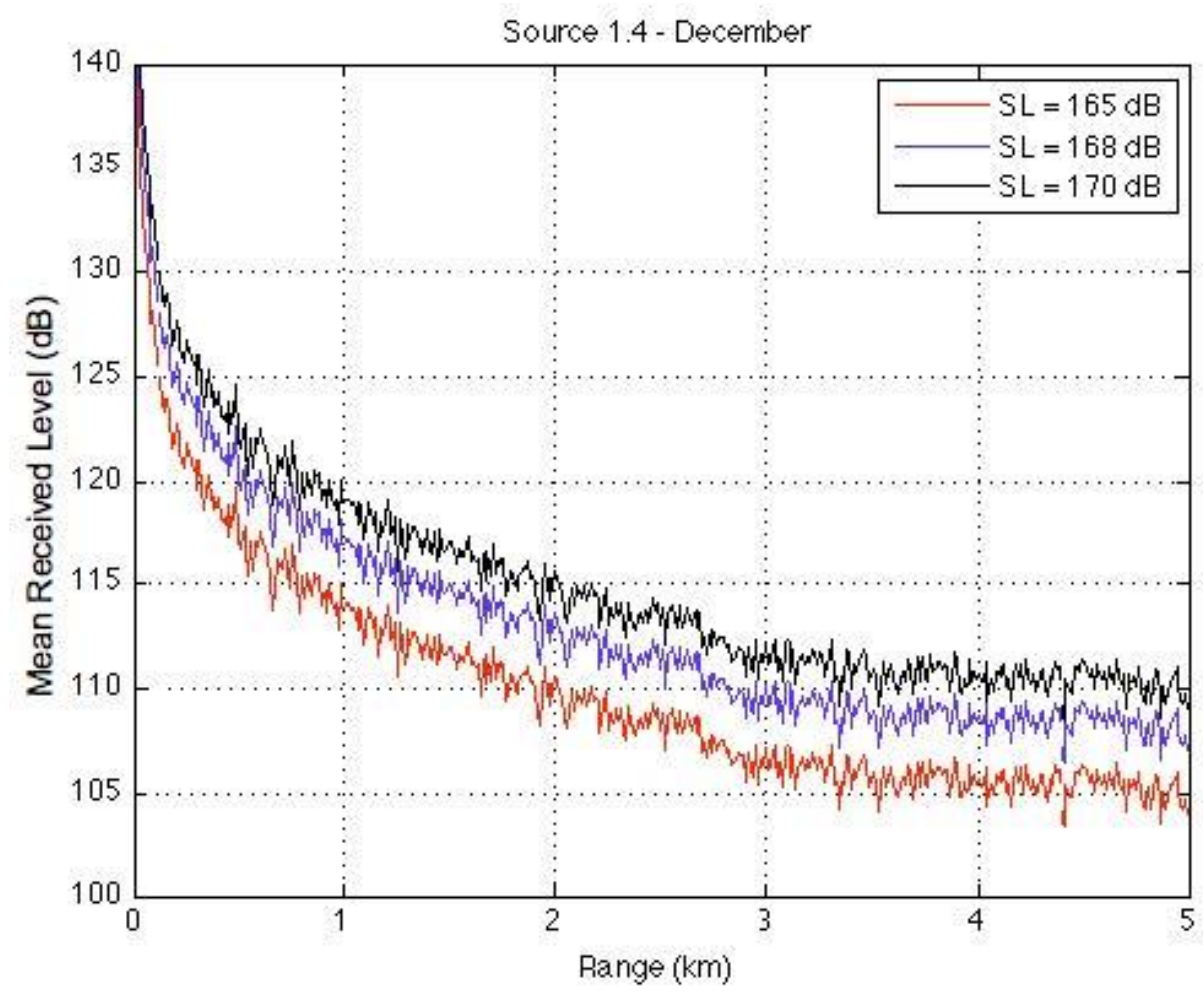

Figure 2: Representative plot of mean received level of sound with increasing distance from source location for a $2 \mathrm{kHz}$ signal projected at a depth of $\mathbf{2 5} \mathrm{m}$ in the water column, $4.6 \mathrm{~km}$ west of Yaquina Head, Oregon, using sound speed profiles for the area measured

The sound source consisted of an Airmar Technology Corporation signal generator (approximately 28.5 $\mathrm{cm} \times 23.5 \mathrm{~cm} \times 15.5 \mathrm{~cm}$ ) and projector (approximately $20 \mathrm{~cm}$ in diameter and $6 \mathrm{~cm}$ thick; Figure 1), connected to four Optima Blue Top D31M batteries. The signal generator was programmed to emit the 
1-s warble three times per minute (once every $20 \mathrm{~s}$ ) during a 6-h experimental period each day and be off for the remainder of the day. A soft-start was programmed into the signal generator to ensure that no animals were exposed to the full source level without prior opportunity to move away from the source. At the beginning of each experimental period the device began transmitting at a source level of $120 \mathrm{~dB}$, and then gradually ramped up to $170 \mathrm{~dB}$ over a 10-min period. The operational schedule of the device included control periods of no sound and experimental periods of active sound emission on a 2-d rotation. On day 1 of this rotation, the sound source was on from 8:00 am until 2:10 pm, with the first 10 minutes being the ramp-up procedure. The source was then turned off. On day 2 of the rotation, the sound source was on from 10:00 am until 4:10 pm, with the first 10 minutes being the ramp-up procedure. Thus, during an 8-h day, there were $6 \mathrm{~h}$ of experimental period and $2 \mathrm{~h}$ of control period, with the latter alternating between afternoon and morning in the 2-d rotation.

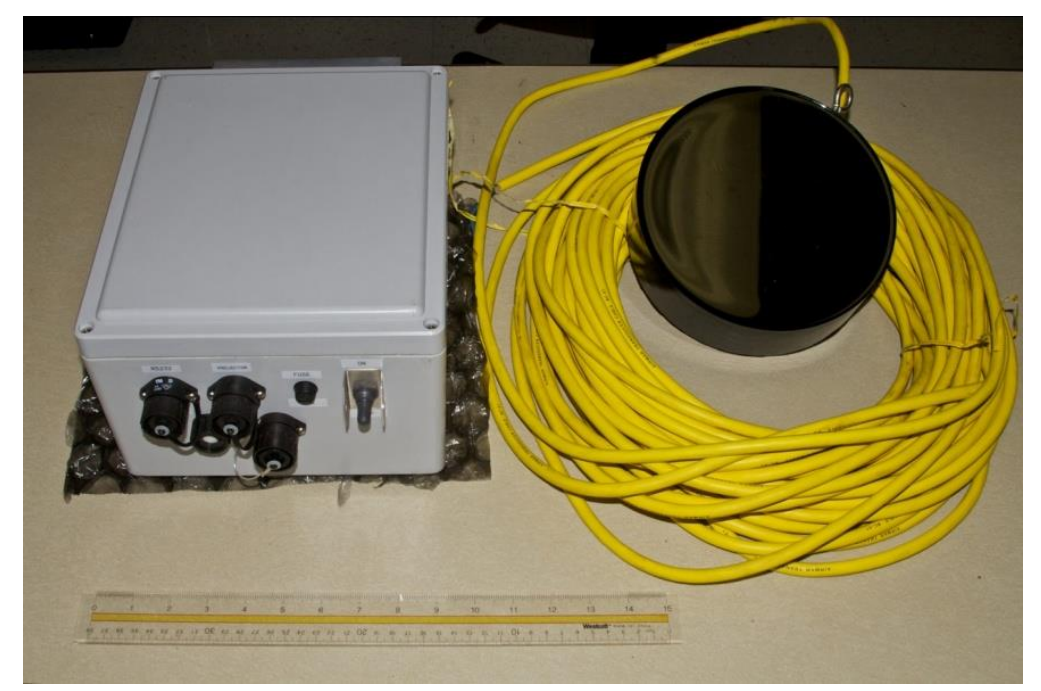

Figure 3: Acoustic deterrent device components, consisting of an Airmar Technology Corporation signal generator (left) and Airmar projector (right).

The signal generator and batteries were installed separately in waterproof/pressure-proof housings designed by The Sexton Company LLC (one for the signal generator and two for the batteries). These housings consisted of 12-inch diameter Schedule 40 PVC tubes with PVC caps on one end and double, oring-grooved acrylic doors on the other end. Waterproof fittings in the acrylic doors and marine underwater cables were used to attach the batteries to the signal generator. The housings were mounted on an aluminum-framed dome-shaped Lander cage, weighing approximately $300 \mathrm{~kg}$, with 183$\mathrm{cm}$ maximum diameter and $170-\mathrm{cm}$ height (Figure 2). Four $23-\mathrm{kg}$ lead plates were attached to each of the four Lander legs for added weight. The device was moored directly west of Yaquina Head, Oregon, at the $50 \mathrm{~m}$ isobar $\left(44.683^{\circ} \mathrm{N}, 124.145^{\circ} \mathrm{W}\right)$ on January 8,2012 , to correspond with depths of locations from the 2007/08 baseline study (Ortega-Ortiz and Mate 2008). This was done using a vessel-mounted crane on board OSU's R/V Elakha. The sound projector (transducer) cable was attached to the signal generator via a waterproof fitting in the acrylic door of the housing and suspended vertically in the water column by a trawl float (Figure 3 ) at a depth of $20 \mathrm{~m}$ below the sea surface. The trawl float was then connected with $35 \mathrm{~m}$ of line to a $56-\mathrm{cm}$ diameter foam buoy at the surface, on which was mounted a pole with a flashing yellow navigation light and radar reflector in accordance with USCG Private Aids to 
Navigation (PATON). A spherical steel cage was manufactured to hold the transducer to provide protection and act as a load frame to prevent damage during deployment and recovery. A secondary line (approximately $36 \mathrm{~m}$ in length) was attached to the Lander and laid out along the seafloor with anchor chain and two large $30 \mathrm{~kg}$ anchor links to serve as a grapple line for recovery, should the original surface buoy become lost. The grapple line was marked at the surface by a low-drag buoy. 


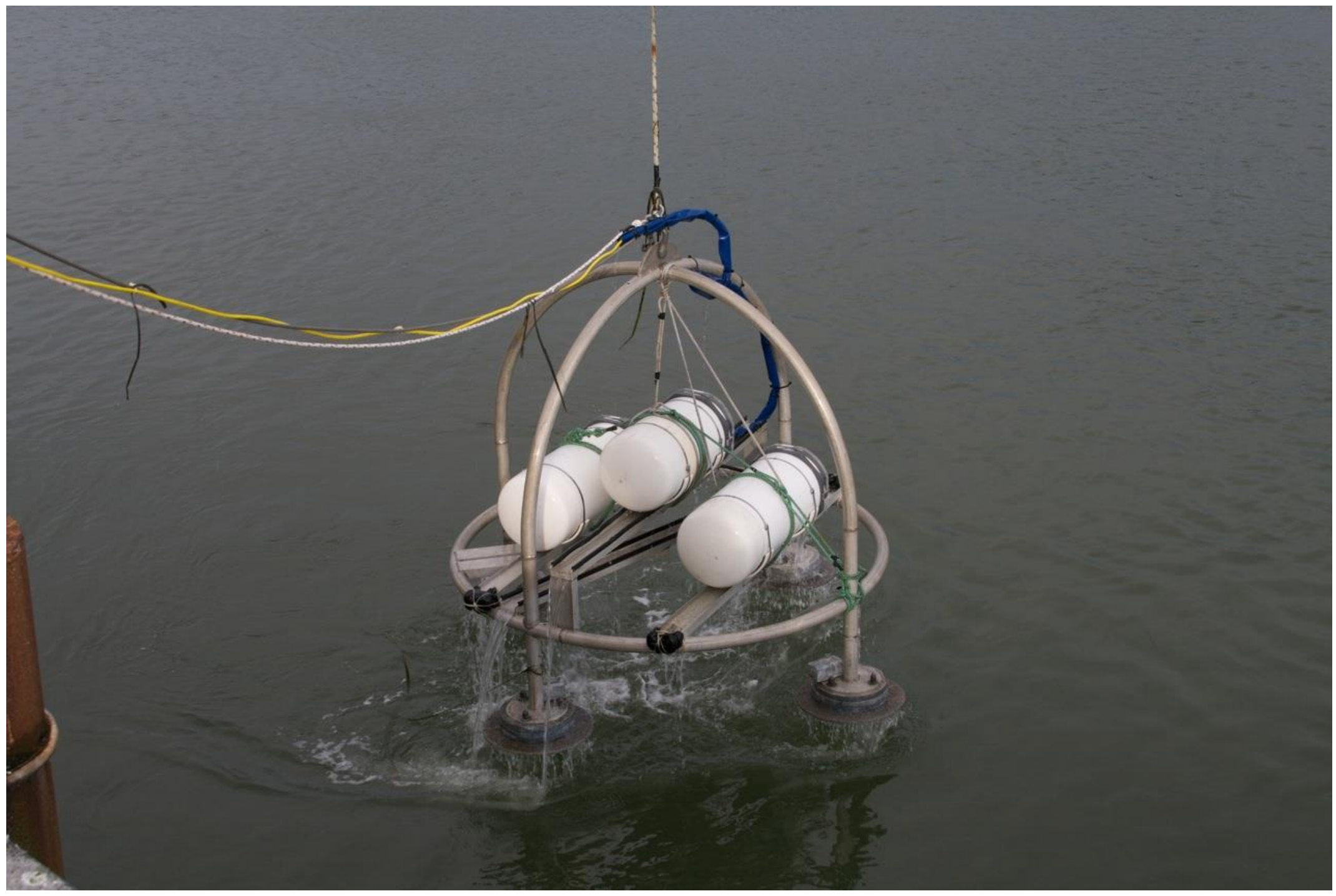

Figure 4: Waterproof housings containing Airmar signal generator and batteries mounted on Lander anchor. 


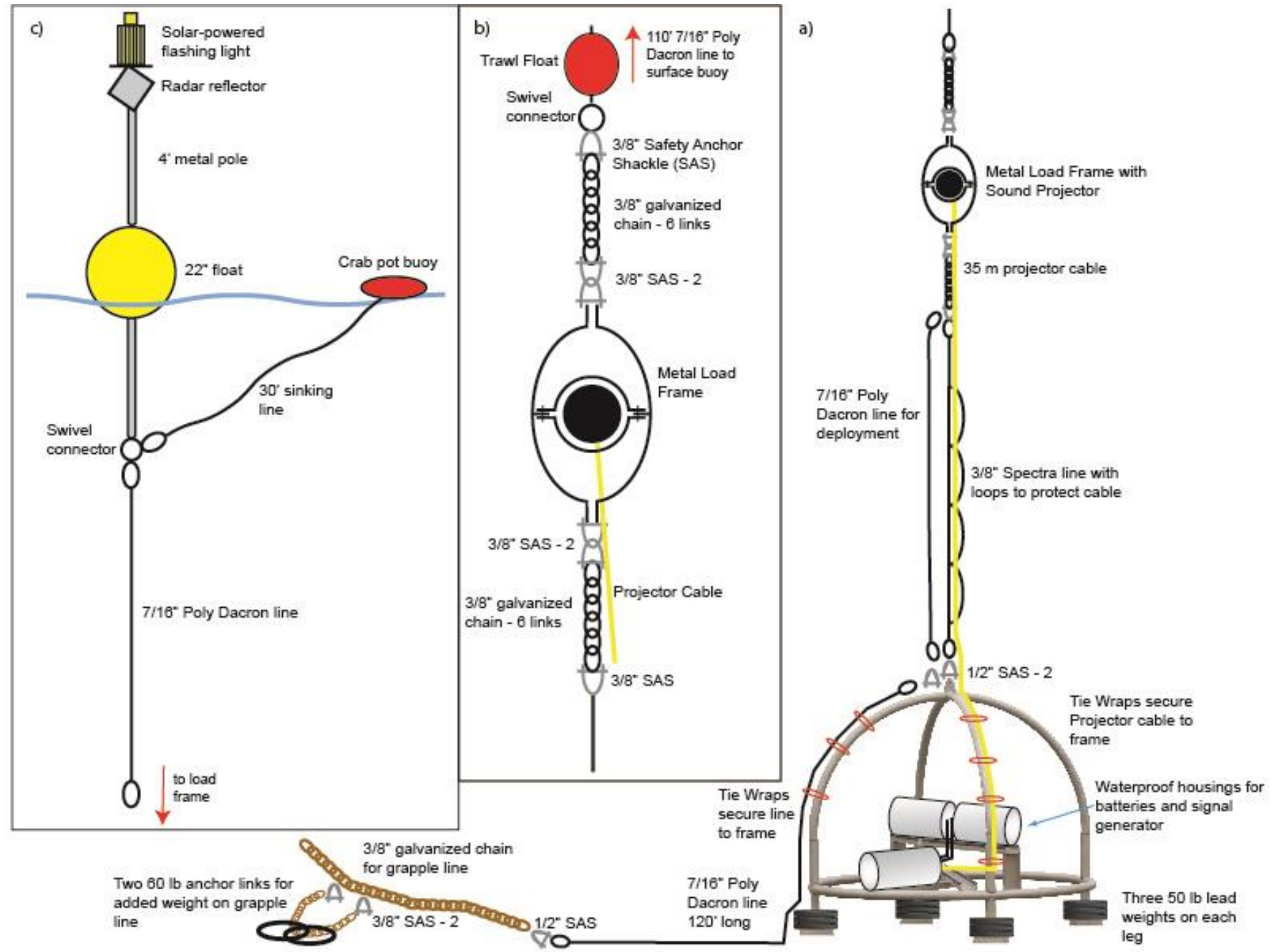

Figure 5: Mooring Schematic. a) Aluminum anchor cage with sound projector mooring and grappling line, b) close-up view of load frame for sound projector, c) surface expression, consisting of buoy, radar reflector, navigation light, and crab pot buoy for easier $r$ 


\section{Shore-based observations of migrating gray whales}

Concurrent with the operation of the acoustic device, shore-based observers carried out theodolite tracking methods from the beginning of January until April 15, 2012, following similar protocols as in the Ortega-Ortiz and Mate (2008) baseline study. These observers operated "blindly" with respect to the acoustic emissions (i.e. they did not know when the sound source was operating). Shore-based theodolite tracking of gray whales took place from an observation station next to the Yaquina Head lighthouse ( $44^{\circ} 40^{\prime} 36.3^{\prime \prime} \mathrm{N}, 124^{\circ} 04^{\prime} 46.4^{\prime \prime} \mathrm{W}, 25.395 \mathrm{~m}$ above sea mean level) during daylight hours, whenever environmental conditions were favorable: no rain, no fog, no haze, wind less than 15 miles per hour and white caps, if present, not numerous (i.e., Beaufort wind force scale $\leq 4)$ ). The observation team consisted of three members: one person searching with $70 \times 50$ handheld binoculars (Fujinon FMTRC-SX), one person handling a digital theodolite with a 30x scope (Sokkia DT210, 2 seconds of arc resolution), and one person recording data into a portable computer. Observers rotated between the three positions, with the height of the theodolite being adjusted for the eye-height of each of the observers.

Observers conducted two types of sampling protocols; scan sampling, and focal follow sampling (OrtegaOrtiz and Mate 2008). In scan sampling, observers surveyed the ocean from 2250 to 3050 in the magnetic compass and from Yaquina Head to the horizon. The 80 degree field of view represented a distance of $3 \mathrm{~km}$ both north and south of the deterrent mooring location. At the beginning of each scan, observers would start at one end of the field of view and focus in a $5^{\circ}$ arc segment for $60 \mathrm{~s}$, searching for whales or whale cues such as blows or splashes. After $60 \mathrm{~s}$, observers would move their focus to the next $5^{\circ}$ segment, and so on. To prevent duplicate counts scan sampling was conducted clockwise during southbound migration, starting at the south end of the scan sector (2250 magnetic) and ending in the north end (3050 magnetic). Conversely, during northbound migration scan sampling was conducted counterclockwise, from 305 to 2250 magnetic. Whenever a whale was sighted, observers recorded azimuth (horizontal) and declination (vertical) angles with the theodolite to estimate distance from the station following the approximation described by Lerczak and Hobbs (1998). The theodolite was connected to a computer running the software package Pythagoras (Gailey and Ortega-Ortiz 2002) which records angle measurements, estimates distance to the whale, and calculates the whale's geographic location.

During focal follow sampling, observers followed individual whales (or whale groups) and obtained multiple theodolite fixes to determine speed and path of the whales as they passed Yaquina Head. Focal follows were conducted in a larger field of view (approximately $200^{\circ}$ to $340^{\circ}$ ) than scan sampling to see if we could detect changes in whale trajectory as they passed the deterrent location. During southbound migration, observers started scanning at the north end of the viewing range, and at the south end of the range during northbound migration, so as to start focal follows as close to the beginning of the whales' discernable path through the "area of interest" as possible.

Observations alternated between scan and focal follow sampling each day, with an attempt to conduct as many of each as possible in an 8-h period between 8:00 am and 4:00 pm. To prevent duplicate counts of the same whale or whale group, subsequent scan samples were separated by the amount of time it took for whales in one scan to have passed through the entire field of view (maximum time of $1 \mathrm{~h}$ ). 
Whale locations were imported into a geographic information system (GIS) with a bathymetry raster layer created with the computer software package ArcMap. Distance to deterrent, distance to shore, and bottom depth (to the nearest $5 \mathrm{~m}$ ) were determined for each location, as well as speed of travel for each focal follow. Distance to the deterrent mooring location was also computed for each whale location collected during scan sampling and also for the focal follow location that came closest to the deterrent during each track.

Data were analyzed to determine whether gray whale distribution and behavior changed in response to the deterrent device. A Chi-square Test of Independence was used to determine if there were significantly fewer locations than expected near the deterrent while the device was on. This test compared the proportion of experimental locations to total locations within $500 \mathrm{~m}$ rings from the deterrent location out to a distance of $3 \mathrm{~km}$.

\section{Results}

Observations were possible on $51 \mathrm{~d}$ between January 1 and April 15, 2012. A total of 137 scans were conducted during $56.9 \mathrm{~h}$ of scan sampling effort (Appendix I). This resulted in 143 whale locations for a total of 243 whales. Fifty-seven focal follows were conducted for a total of $63.3 \mathrm{~h}$ of focal follow effort (Appendix II). During these focal follows 546 whale locations were obtained for a total of 142 whales.

Inclement weather and equipment problems resulted in very small sample sizes, especially during experimental periods, when the deterrent was transmitting. A storm in mid-January, with $>100 \mathrm{mph}$ winds and $>30$ foot seas, broke off the surface buoy from the transducer mooring. The buoy was recovered on Copalis Beach in Washington and re-attached on January 28 to the low drag buoy marking the grapple line. Two days later all surface buoys broke free as commercial crabbing gear was dragged over the line causing it to part from the grapple line on the bottom. The deterrent was then no longer marked at the surface, and as a result, we were unable to recover it mid-season to change the batteries. As the batteries faded, the time between transmissions increased above the desired $20 \mathrm{~s}$ duty cycle, until they stopped all together at battery exhaustion. In-field recordings of the deterrent were made on January 28 and February 11, at which time the deterrent was transmitting every $20 \mathrm{~s}$ as expected. Recordings made on March 3 showed the deterrent transmitting once every 2-3 minutes. On March 9 the deterrent was no longer transmitting. The period of time between February 12 and March 8 was then a period of unknown deterrent function and considered a "non-operational" period. The period after March 8 was also considered non-operational due to our inability to install new batteries in the device, resulting in no experimental samples during northbound migration. The period between deployment on January 8 and February 11 was considered good, having both experimental and control periods as expected. Three days of southbound observations prior to deployment were combined with this period and collectively considered the "operational period" for the study. Only operational period data were included in the analysis of deterrent effect. Both non-operational and operational periods were included in basic migration pattern analyses, such as distances to shore and bottom depths.

Weather prevented observations at the start of the year, so the first day of observations was on January 3,2012 . The first whale was sighted on January 3 , with the peak of southbound migration occurring on 
January 8 at 16.4 whales/h (southbound $\bar{x}=4.0 \pm 5.02$ whales/h, Figure 4 ). The migration phases overlapped this year, with the first northbound whale sighted on February 9 and the last southbound whale sighted on February 15. The peak of northbound Phase A migration occurred on April 6 at 7.6 whales/h (northbound Phase $A \bar{x}=3.2 \pm 2.36$ whales/h). No observations were conducted during northbound Phase B migration.

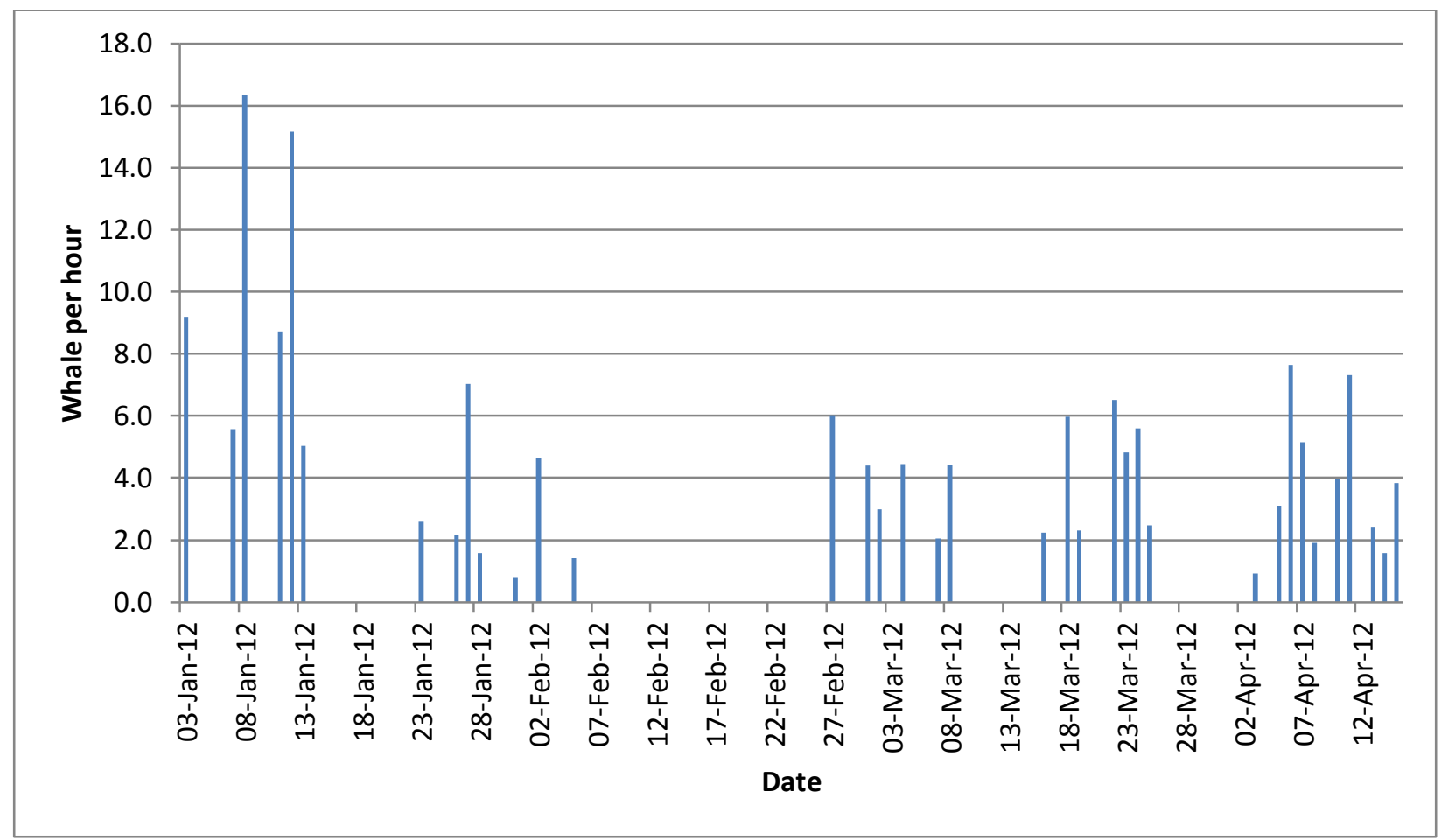

Figure 6: Number of whales per hour located during scan surveys conducted at Yaquina Head, Oregon, from January 3 - April $15,2012$.

Distance to shore for scan locations ranged from $1.8-18.0 \mathrm{~km}(\bar{x}=7.78 \pm 3.68 \mathrm{~km}$, Figure 7) and did not differ significantly between southbound and northbound Phase A migration phases (ANOVA $p=0.26$ ). The average distance to shore was calculated for each focal follow, and ranged from 0.8-12.4 km ( $\bar{x}=$ $5.84 \pm 2.95 \mathrm{~km}$, Figures 8 and 9). These distances also did not differ significantly between the two migration phases (ANOVA $p=0.17$ ). 


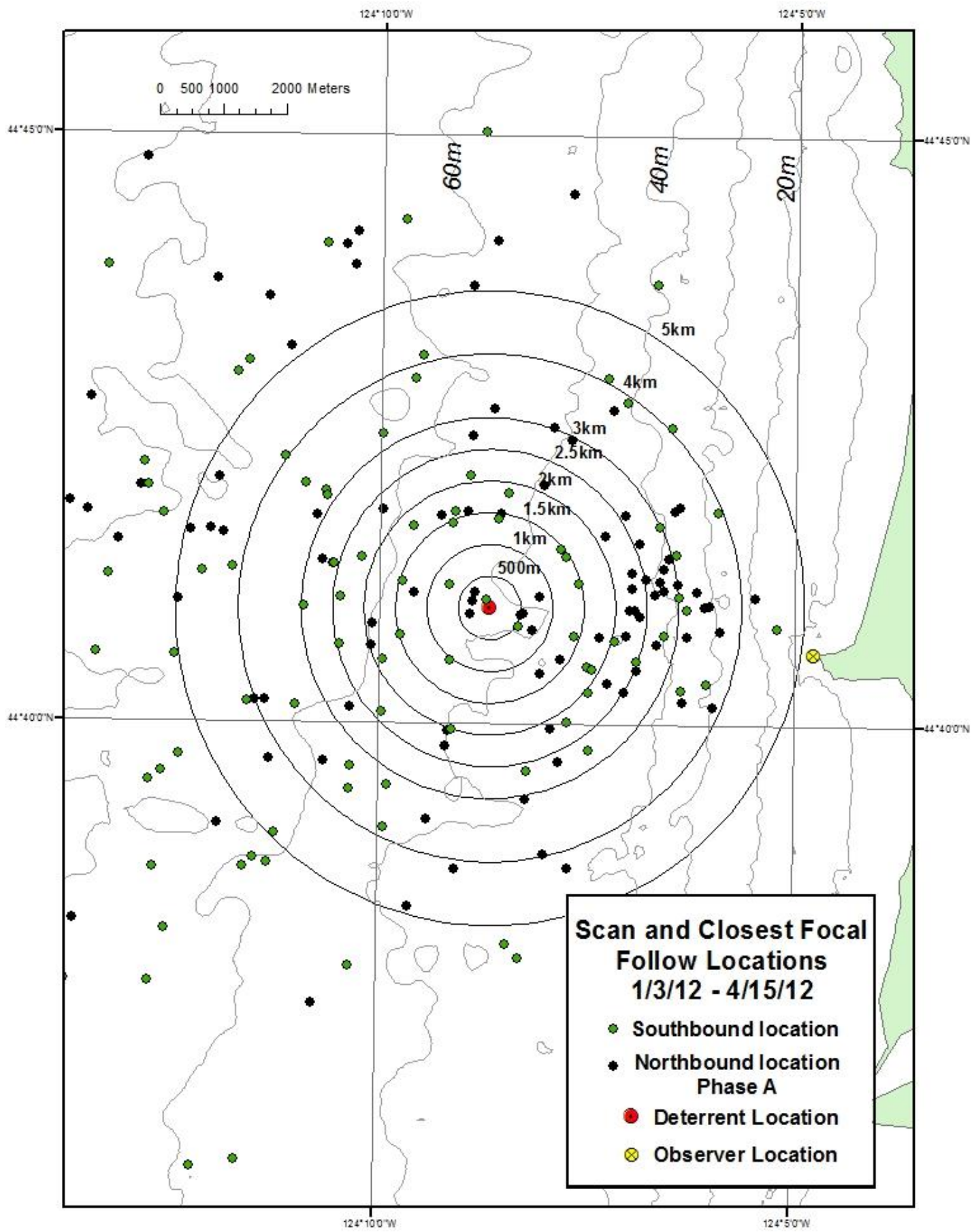

Figure 7: Gray whale locations obtained during scan sampling and focal follow surveys conducted at Yaquina Head, Oregon, from January 3 - April 15, 2012. 


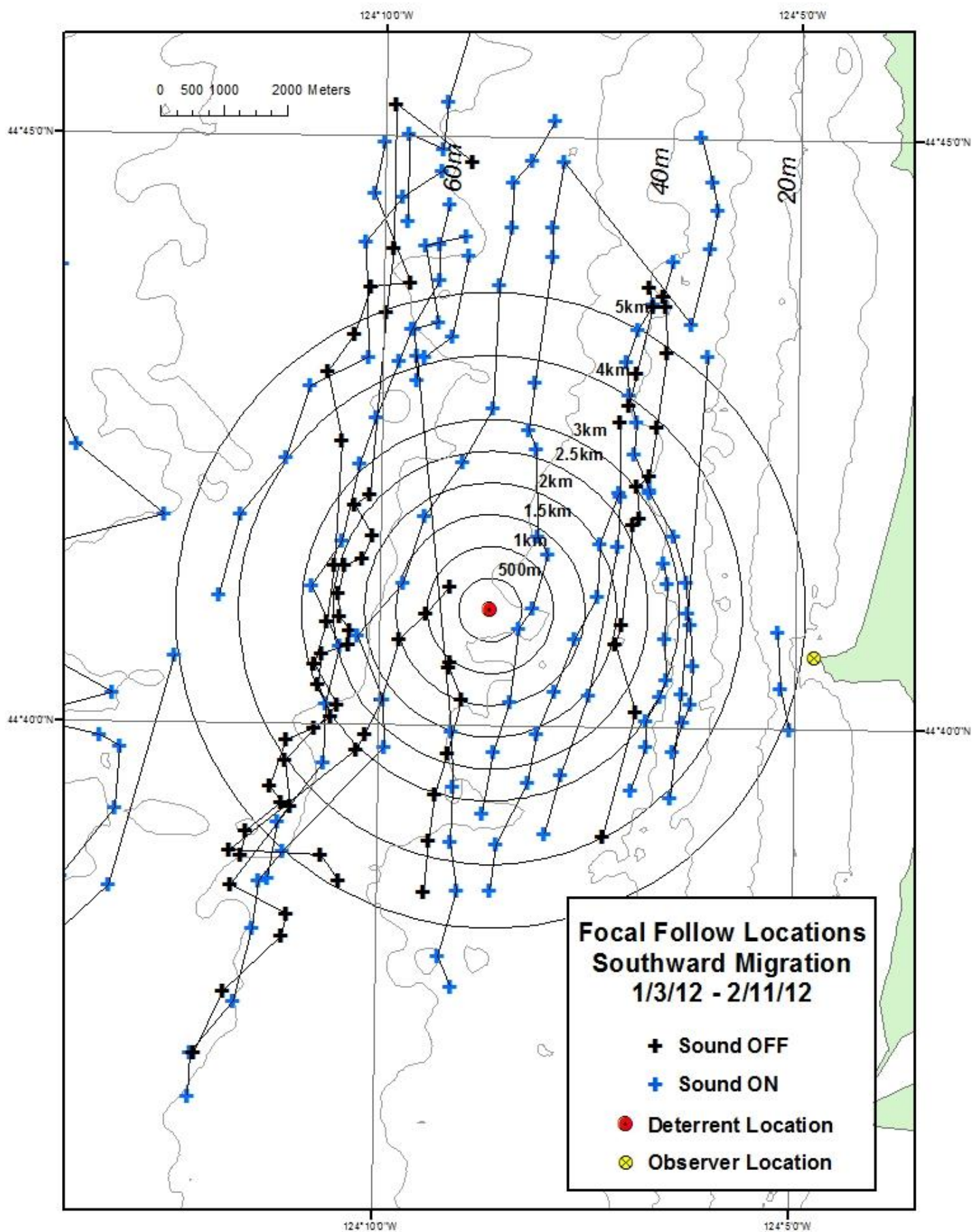

Figure 8: Locations of southbound gray whales obtained during focal follow sampling conducted at Yaquina Head, Oregon, from January 3 - February 11, 2012. 


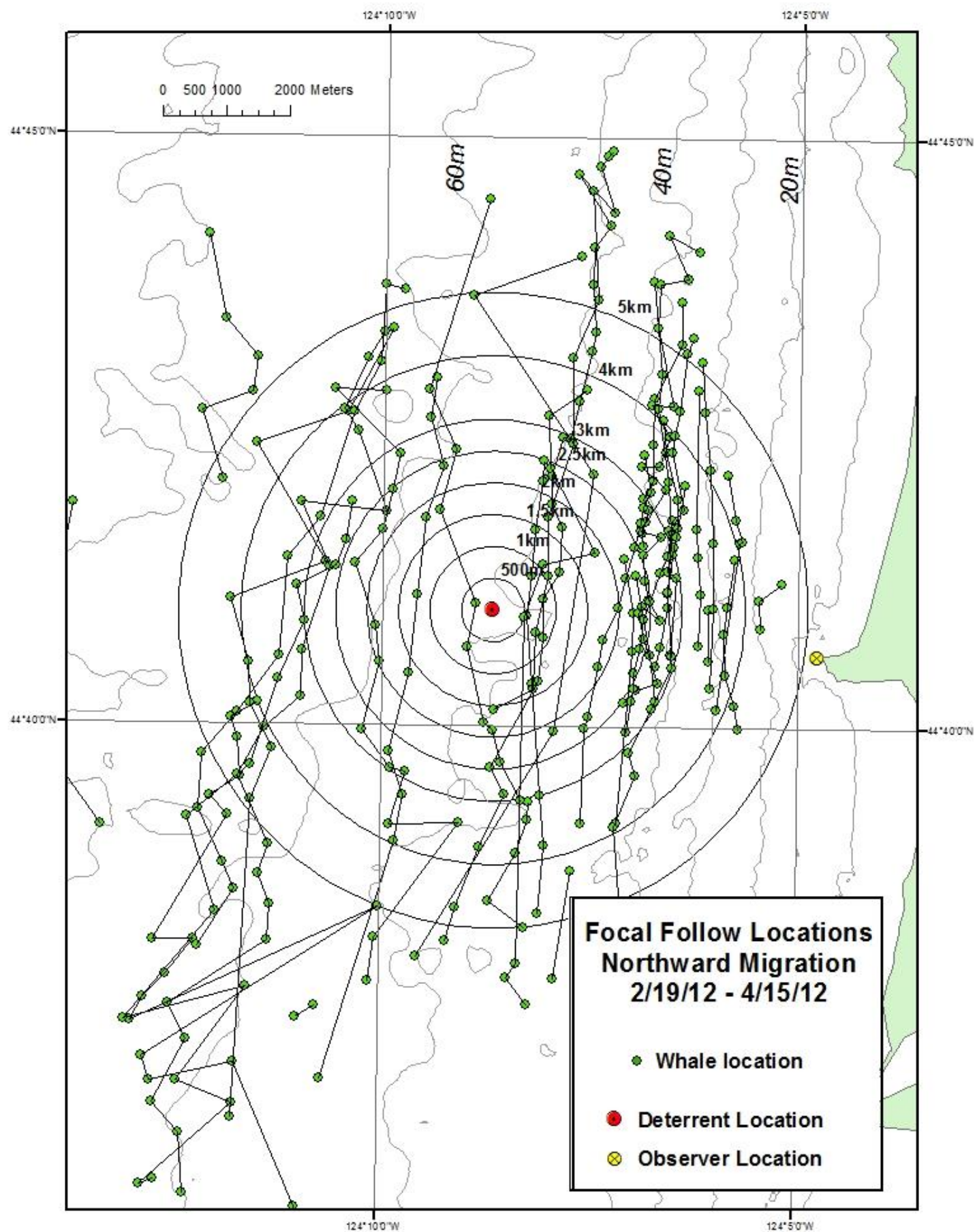

Figure 9: Locations of northbound gray whales obtained during focal follow sampling conducted at Yaquina Head, Oregon, from February 19 - April 15, 2012. 
Bottom depths of gray whale locations recorded during scan sampling ranged from $25-85 \mathrm{~m}(\bar{x}=57.4 \pm$ $12.5 \mathrm{~m}$ ) and did not differ significantly between southbound and northbound Phase A migration phases (ANOVA $p=0.80)$. Average bottom depths for focal follows ranged from $15-74 \mathrm{~m}(\bar{x}=49 . \mathrm{s} \pm 13.1 \mathrm{~m})$ and also did not differ significantly between the two migration phases (ANOVA $p=0.14$ ).

Distance to the deterrent was calculated for all scan locations as well as for the closest location to the deterrent in each focal follow (Table 1). Of the combined 95 locations collected during the operational period, only 34 were within $3 \mathrm{~km}$ of the deterrent: 17 during experimental periods (active sound transmission) and 17 during control periods. Statistical analysis of the proportions of experimental locations in $500 \mathrm{~m}$ rings from the deterrent did not show a significant difference between the hypothesized zone of influence (within $500 \mathrm{~m}$ of the deterrent) and areas out to $3 \mathrm{~km}$ (Chi-square Test of Independence $p=0.86$, Figure 10) . Unfortunately, due to the small sample size, especially the small numbers during experimental periods, the power of the test would not have been sufficient to detect a difference.

Table 1: Frequency and cumulative count of locations located within specified distances to the deterrent mooring location. Both scan sample locations and closest location to the deterrent during each focal follow are included for the period of time when the deterrent was operational (Jan 3 - Feb 112012 ).

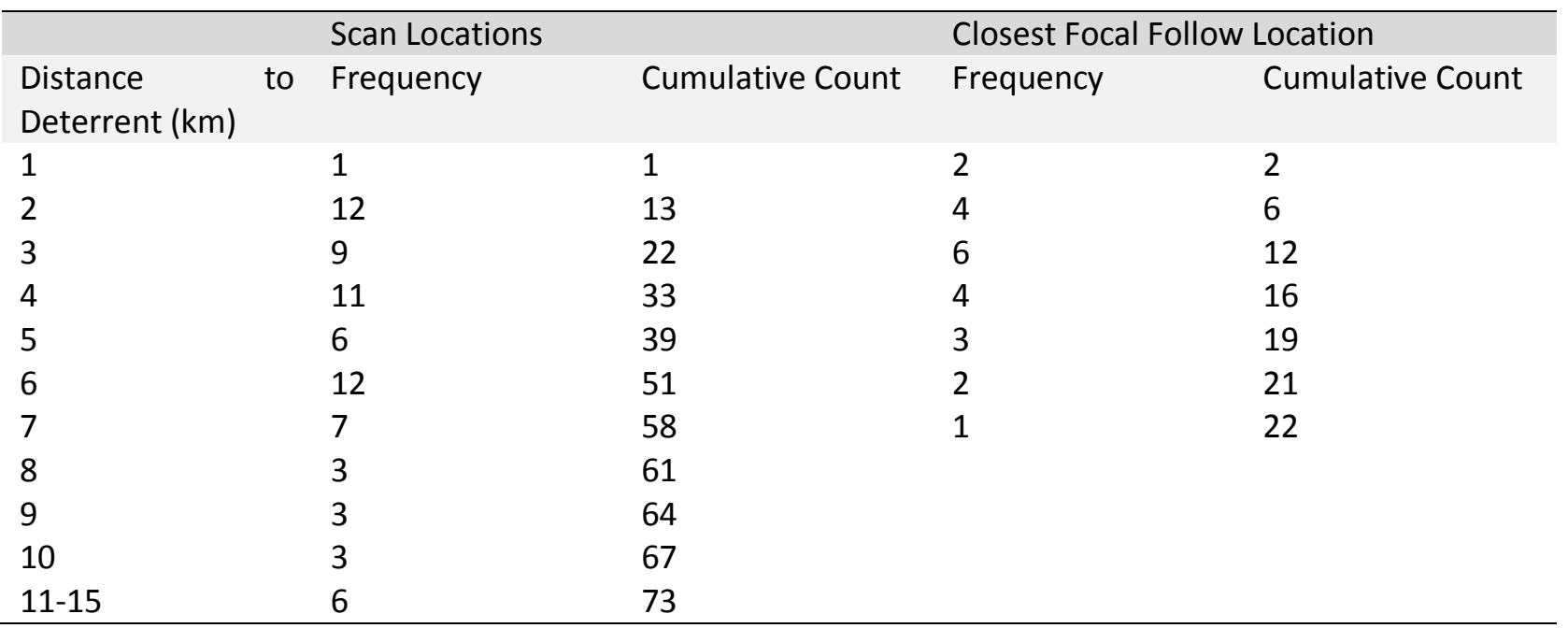




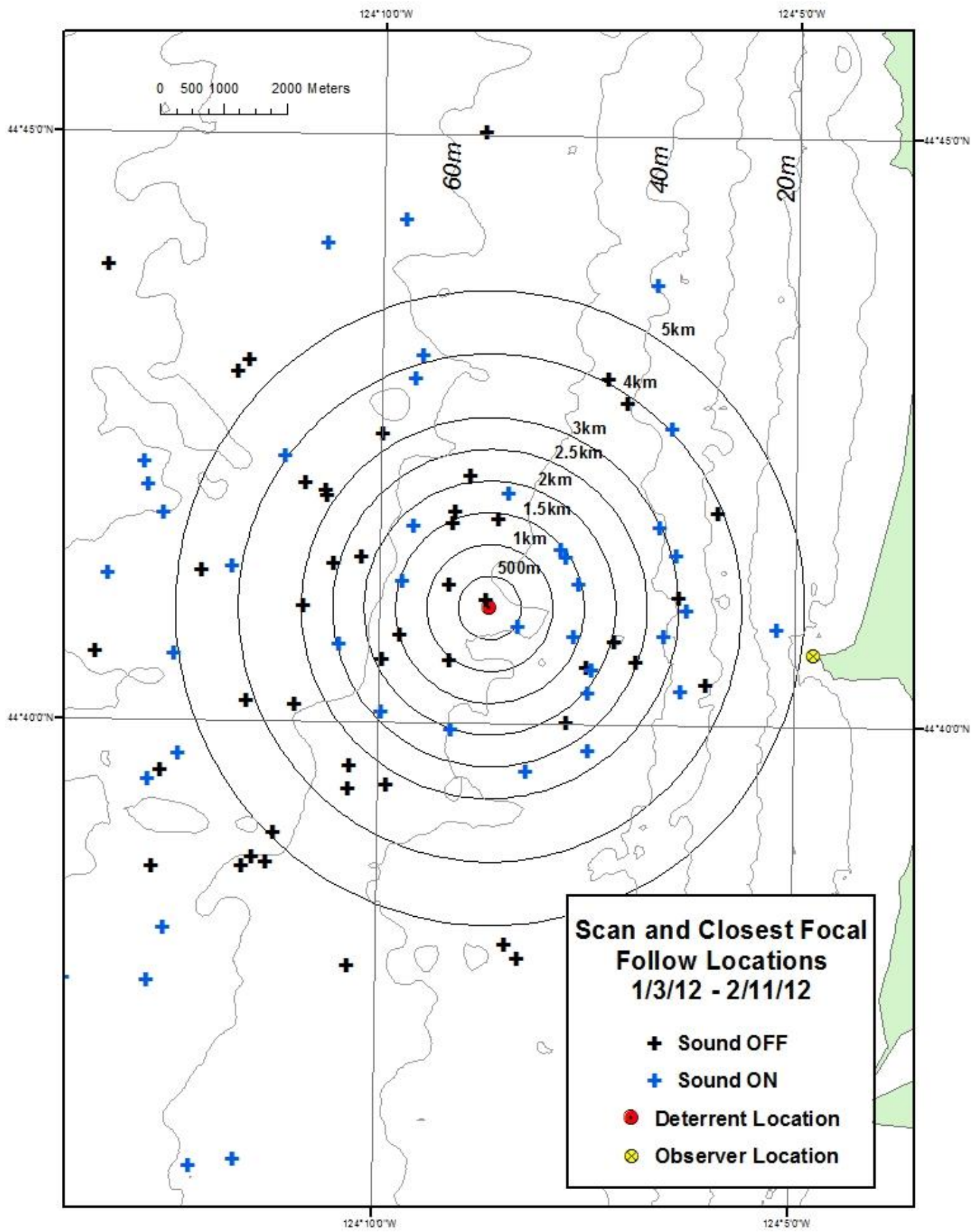

Figure 10: Gray whale locations obtained during scan sampling and focal follow surveys conducted at Yaquina Head, Oregon, during the time the deterrent was operational (Jan 3 - Feb 11, 2012). 
Visual inspection of tracklines obtained during focal follow sampling did not reveal any obvious changes in trackline heading. Due to this and the small sample sizes, we did not conduct quantitative analyses on the tracklines. Had there been enough data, we would have analyzed tracklines using linear regression techniques. Trackline headings would have been calculated using the slope of the best linear fit in the regression. Tracklines that pass the acoustic device would be split into two; the approaching track, and the departing track. Slopes would be compared between experimental and control tracklines and between approaching or departing tracklines to determine if there were differences in headings.

Trackline speeds ranged from $1.5-14.3 \mathrm{~km} / \mathrm{h}(\bar{x}=6.98 \pm 1.86 \mathrm{~km} / \mathrm{h})$, and did not differ significantly between southbound and northbound migration (ANOVA $p=0.18$ ). There was also no significant difference in trackline speeds between experimental and control periods (ANOVA $p=0.32$ ), but, as with scan locations, the power to detect a difference was low because of the small sample sizes.

\section{Discussion}

Due to inadequate sample sizes, the results of this study were inconclusive. The loss of surface buoys due to extreme weather and damage from commercial crabbing gear prevented the recovery of the deterrent mid-season to change batteries. As a result, only the experimental periods for the first 35 days of the study were usable for testing. Additionally, the hypothesized zone of influence was so small (500 $\mathrm{m}$ ) that few whales traveled within that zone, even during control periods. We feel that another season of field testing is warranted to successfully test the effectiveness of the deterrent, but recommend increasing the zone of influence to $3 \mathrm{~km}$ to ensure the collection of adequate sample sizes.

A power analysis using a simplified hypothesis (comparing the proportion of experimental locations within $3 \mathrm{~km}$ of the device to the proportion $3-5 \mathrm{~km}$ of the device) revealed a required sample size of 130 locations divided equally between experimental and control periods ( $\alpha=0.05$ and $\beta=0.80$ ). The number of locations obtained within $5 \mathrm{~km}$ of the device during the current study was 137 . By prioritizing scan sampling and shortening focal follow tracking to concentrate on the area near the deterrent (as opposed to more time-consuming longer distance focal follows), we are confident we can obtain the required sample size with another season of observations.

Modifications have been made to increase the power of the acoustic transducer to accomplish the new $3 \mathrm{~km}$ zone of influence. Connections between the surface buoy and the transducer will be reinforced to ensure the instrument and its surface expression will withstand extreme weather conditions and interactions with crabbing gear. Additionally we will attach twice as many batteries to the signal generator as in the current study eliminating the need to change batteries mid-season.

We are quite confident that with the above changes we will be able to determine whether the deterrent is effective at deflecting gray whales. A successful deterrent device may serve as a valuable mitigation tool to protect gray whales in the event that hydrokinetic energy development poses a collision or entanglement risk. It may also be applicable to endangered baleen whales in the Outer Continental Shelf, such as blue, fin, and humpbacks, as hydrokinetic energy development moves offshore into their habitat. Such a device may also have value as mitigation for other potentially harmful situations, such as oil spills or when whales stray out of their natural habitat and are in danger of stranding or starvation. 


\section{Acknowledgements}

This project was funded by the U.S. Department of Energy, through a sub-agreement with Pacific Energy Ventures LLC under Award Number DE-EE0002660. This work was also supported in part by the Oregon Wave Energy Trust, the Northwest National Marine Renewable Energy Center, and Oregon State University's Marine Mammal Endowment. The U.S. Bureau of Land Management's Yaquina Head Outstanding Natural Area allowed us to conduct our observations from the deck in front of Yaquina Head Lighthouse and provided logistical support. This project was conducted under the authorization of National Marine Fisheries MMPA/ESA Research/Enhancement Permit No. 15483 and Oregon State University Institutional Animal Care and Use Committee Permit No. 4099. We'd like to thank Steve Christensen, Fred Boericke, Dan Fladung, and Kenneth Rolt of Airmar Technology Corporation for development of the acoustic device. We'd also like to thank Erin Kunisch and Alan Low for their tireless efforts as primary observers, in addition to the lead author, at Yaquina Head Lighthouse. We thank Tomas Follett, Craig Hayslip, Ladd Irvine, John McClung, and Dori Dick for filling in as observers when needed. We thank Gary Archambeau, Chris Burns, Maureen Doherty, Jane Holbrooks, Barry McPherson, Robbin Spraitz, Thom Strunk, and Linda Taylor for their volunteer efforts at Yaquina Head to educate public visitors about our study. We thank Dave Mellinger, Holger Klinck, and Elizabeth Thorp Küsel of Oregon State University for development of the acoustic propagation model and Holger Klinck, Elizabeth Thorp Küsel, Yang Lu, and Sharon Nieukirk for calibrated hydrophone testing of the transducer. We thank Joe Haxel, Sara Heimlich, Toby Martin, Jay Simpkin, Daryl Swensen, and Walt Waldorf for mooring advice. We thank Ken Serven, Ron Briggs, and Craig Hayslip for mooring construction and assembly and for help during deployment and recovery of the acoustic device. We thank Ken Sexton for the manufacture of the waterproof housings and help with deployment. We'd also like to thank Mike Kriz and Cody Robinson, captain and crew of the R/V Elakha, for deployment of the acoustic device off Yaquina Head. We thank Lt. Olivia Hauser and the captain and crew of the NOAA ship Rainier launch for helping us locate the acoustic device after loss of the surface buoy. We thank OSU scientific divers, Kevin Buch, Jacob Metger, Gayle Orner, Daryl Swensen, and Walt Waldorf for diving assistance during recovery of the device, as well as Ladd Irvine, Jim Rice, and Tomas Follett for assistance during recovery on board the R/V Pacific Storm. We thank Kathy Minta for award administration, and Sheri Woods and Bonnie Anderson-Becktold for clerical assistance.

Disclaimer: "This report was prepared as an account of work sponsored by an agency of the United States Government. Neither the United States Government nor any agency thereof, nor any of their employees, makes any warranty, expressed or implied, or assumes any legal liability or responsibility for the accuracy, completeness, or usefulness of any information, apparatus, product, or process disclosed, or represents that is use would not infringe privately owned rights. Reference herein to any specific commercial product, process, or service by trade name, trademark, manufacturer, or otherwise does not necessarily constitute or imply its endorsement, recommendation, or favoring by the United States Government or any agency thereof. Their views and opinions of the authors expressed herein do not necessarily state or reflect those of the United States Government or any agency thereof." 


\section{Literature Cited}

Boehlert, G.W., G.R. McMurray and C.E. Tortorici, Eds. 2008. Ecological effects of wave energy in the Pacific Northwest. U.S. Dept. Commerce, NOAA Tech. Memo. NMFS-F/SPO-92.

Calambokidis, J., J.D. Darling, V. Deecke, P. Gearin, M. Gosho, W. Megill, C.M. Tombach, D. Goley, C. Toropova and B. Gisborn. 2002. Abundance, range and movements of a feeding aggregation of gray whales (Eschrichtius robustus) from California to southeastern Alaska in 1998. Journal of Cetacean Research and Management 4:267-276.

Calambokidis, J., A. Klimek and L. Schlender. 2009. Summary of collaborative photographic identification of gray whales from California to Alaska for 2007. Final Report for Purchase Order AB133F-05SE-5570.

Darling, J. D. 1984. Gray whales off Vancouver Island, British Columbia. Pp. 267-287 in Jones, M. L., S. L. Swartz, and S. Leatherwood (eds.), The gray whale, Eschrichtius robustus. Academic Press, Inc., Orlando.

Dolman, S. and Simmonds, M. 2010. Towards best environmental practice for cetacean conservation in developing Scotland's marine renewable energy. Marine Policy, 34: 1021-1027.

Gailey, G. A. and J. Ortega-Ortiz. 2002. A note on a computer-based system for theodolite tracking of cetaceans. Journal of Cetacean Research Management 4:213-218.

Gill, A. B. 2005. Offshore renewable energy: ecological implications of generating electricity in the coastal zone. Journal of Applied Ecology, 42: 605-615.

Green, G.A., J.J. Brueggeman, R.A. Grotefendt and C.E. Bowlby. 1995. Offshore distances of gray whales migrating along the Oregon and Washington coasts, 1990. Northwest Science 69:223-227.

Herzing, D.L. and B.R. Mate. 1984. Gray Whale Migrations along the Oregon Coast, 1978-1981. Pages 289-307 in M. L. Jones, S. Swartz and S. Leatherwood, eds. The Gray Whale: Eschrichtius robustus. Academic Press, Orlando, Fla.

Küsel, E., H. Klinck and D. Mellinger. 2009. Acoustic propagation modeling offshore Newport, Oregon. Personal communication.

Lerczak, J. A. and R. C. Hobbs. 1998. Calculating sighting distances from angular readings during shipboard, aerial, and shore-based marine mammal surveys. Marine Mammal Science 14:590599.

Malme, C. I., P. R. Miles, C. W. Clark, P. Tyack, and J. E. Bird. 1983. Investigations of the potential effects of underwater noise from petroleum industry activities on migrating gray whale behavior. BBN Rep. 5366. Rep. from Bolt Beranek and Newman Inc., Cambridge, MA, for U.S. Minerals Manage. Serv., Anchorage, AK. NTIS PB86-174174. 
Malme, C. I., Miles, P. R., Clark, C. W., P. Tyack, and J. E. Bird. 1984. Investigations of the potential effects of underwater noise from petroleum industry activities on migrating gray whale behavior/Phase II: January 1984 migration. BBN Rep. 5586. Report from Bolt Beranek and Newman Inc., Cambridge, MA, for U.S. Minerals Management Service, Anchorage, AK. NTIS PB86-218377.

Mate, B.R. and A. Poff. 1999. The southbound migration of gray whales, winter 1998/99. NOAA Technical Memorandum NMFS-AFSC-103:48.

Nerini, M. 1984. A review of gray whale feeding ecology. Pages 423-450 in M. L. Jones, S. Swartz and S. Leatherwood, eds. The Gray Whale: Eschrichtius robustus. Academic Press, Orlando, Fla.

Newell, C.L. and T.J. Cowles. 2006. Unusual gray whale Eschrichtius robustus feeding in the summer of 2005 off the central Oregon Coast. Geophysical Research Letters 33:L22S11.

NOAA 2011. National Oceanic and Atmospheric Administration. Office of Protected Resources Marine Mammal Stock Assessment Reports (SARS) by Species/Stock. Gray whale (Eschrichtius robustus): Eastern North Pacific Stock. Available at: http://www.nmfs.noaa.gov/pr/sars/species.htm

Ortega-Ortiz, J. G. and Lagerquist, B. A. 2009. Report of the workshop on potential effects of wave energy buoys on marine mammals of the Oregon coast. Report submitted to the Oregon Wave Energy Trust, Portland, OR. Available at: http://www.oregonwave.org/marine-mammal-study/

Ortega-Ortiz, J.G. and B.R. Mate. 2008. Distribution and movement patterns of gray whales migrating by Oregon: Shore-based observations off Yaquina Head, Oregon, December 2007-May 2008. Report submitted to the Oregon Wave Energy Trust. 34 pp. Available at: http://www.oregonwave.org/marine-mammal-study/

Poole, M.M. 1984. Migration corridors of gray whales along the central California coast, 1980-1982. Pages 389-407 in M. L. Jones, S. Swartz and S. Leatherwood, eds. The Gray Whale: Eschrichtius robustus. Academic Press, Orlando, Fla.

Rice, D.W. and A.A. Wolman. 1971. The life history and ecology of the gray whale, Eschrichtius robustus. Am. Soc. Mammal. Special Publication 3. 142 pp.

Rice, D.W., A.A. Wolman and H.W. Braham. 1984. The gray whale, Eschrichtius robustus. Marine Fisheries Review 46:7-14.

Wilson, B. R., Batty, S., Daunt, F. and Carter, C. 2007. Collision risks between marine renewable energy devices and mammals, fish and diving birds. Report to the Scottish Executive. Scottish Association for Marine Science, Oban, Scotland, PA37 1QA.

U.S. Department of Energy. 2012. Final Environmental Assessment for the Oregon State University and Northwest National Marine Renewable Energy Center Wave Energy Test Project. U.S. Department of Energy, Golden Field Office, Golden, Colorado. 


\section{Appendix I}

Table 1. Scan sampling events obtained during shore-based observations of migrating gray whales at Yaquina Head, Oregon, from January 3 - April 15, 2012, detailing number of whales/whale groups located and total number of whales.

\begin{tabular}{|c|c|c|c|c|c|c|c|}
\hline Scan & Date & $\begin{array}{l}\text { Start } \\
\text { Time }\end{array}$ & $\begin{array}{l}\text { End } \\
\text { Time }\end{array}$ & $\begin{array}{l}\text { Duration } \\
\text { (h:m:s) }\end{array}$ & $\begin{array}{l}\text { Number of } \\
\text { whales/whale } \\
\text { groups }\end{array}$ & $\begin{array}{l}\text { Total } \\
\text { number } \\
\text { of whales }\end{array}$ & $\begin{array}{l}\text { Migration } \\
\text { Heading }\end{array}$ \\
\hline 1 & 03-Jan-12 & $10: 36: 51$ & $11: 02: 59$ & $0: 26: 08$ & 2 & 4 & $\mathrm{~S}$ \\
\hline 2 & 06-Jan-12 & $12: 11: 40$ & $12: 27: 32$ & $0: 15: 52$ & 0 & 0 & $S$ \\
\hline 3 & 7-Jan-12 & $10: 10: 15$ & $10: 43: 41$ & $0: 33: 26$ & 0 & 0 & $S$ \\
\hline 4 & 7-Jan-12 & $11: 23: 59$ & $12: 21: 17$ & $0: 57: 18$ & 1 & 1 & $S$ \\
\hline 5 & 7-Jan-12 & $13: 05: 07$ & $13: 54: 31$ & $0: 49: 24$ & 5 & 10 & $S$ \\
\hline 6 & 7-Jan-12 & $14: 29: 00$ & $15: 00: 56$ & $0: 31: 56$ & 3 & 5 & $S$ \\
\hline 7 & 8-Jan-12 & $14: 06: 23$ & $15: 27: 05$ & $1: 20: 42$ & 12 & 22 & $S$ \\
\hline 8 & 11-Jan-12 & $9: 37: 44$ & 10:01:29 & $0: 23: 45$ & 1 & 2 & $S$ \\
\hline 9 & 11-Jan-12 & $10: 37: 59$ & $11: 14: 38$ & $0: 36: 39$ & 1 & 1 & $S$ \\
\hline 10 & 11-Jan-12 & 11:48:31 & $12: 48: 55$ & 1:00:24 & 5 & 9 & $S$ \\
\hline 11 & 11-Jan-12 & $14: 44: 58$ & $15: 29: 21$ & $0: 44: 23$ & 5 & 12 & $S$ \\
\hline 12 & 12-Jan-12 & $10: 33: 24$ & $11: 46: 40$ & 1:13:16 & 7 & 15 & $S$ \\
\hline 13 & 12-Jan-12 & $14: 13: 43$ & 15:11:03 & $0: 57: 20$ & 12 & 18 & $S$ \\
\hline 14 & 13-Jan-12 & 9:08:33 & $10: 05: 26$ & $0: 56: 53$ & 5 & 8 & $S$ \\
\hline 15 & 13-Jan-12 & $12: 56: 53$ & $13: 25: 07$ & $0: 28: 14$ & 1 & 1 & $S$ \\
\hline 16 & 13-Jan-12 & $14: 30: 41$ & $14: 53: 03$ & $0: 22: 22$ & 0 & 0 & $S$ \\
\hline 17 & 23-Jan-12 & $11: 31: 38$ & $11: 55: 26$ & $0: 23: 48$ & 0 & 0 & $\mathrm{~S}$ \\
\hline 18 & 23-Jan-12 & $12: 21: 26$ & $12: 38: 22$ & $0: 16: 56$ & 0 & 0 & $S$ \\
\hline 19 & 23-Jan-12 & $13: 45: 55$ & $14: 14: 47$ & $0: 28: 52$ & 2 & 3 & $S$ \\
\hline 20 & 26-Jan-12 & $12: 20: 11$ & 12:49:09 & $0: 28: 58$ & 1 & 1 & $S$ \\
\hline
\end{tabular}




\begin{tabular}{|c|c|c|c|c|c|c|c|}
\hline Scan & Date & $\begin{array}{l}\text { Start } \\
\text { Time }\end{array}$ & $\begin{array}{l}\text { End } \\
\text { Time }\end{array}$ & $\begin{array}{l}\text { Duration } \\
\text { (h:m:s) }\end{array}$ & $\begin{array}{l}\text { Number of } \\
\text { whales/whale } \\
\text { groups }\end{array}$ & $\begin{array}{l}\text { Total } \\
\text { number } \\
\text { of whales }\end{array}$ & $\begin{array}{l}\text { Migration } \\
\text { Heading }\end{array}$ \\
\hline 21 & 26-Jan-12 & $13: 30: 38$ & $13: 56: 59$ & $0: 26: 21$ & 1 & 1 & $\mathrm{~S}$ \\
\hline 22 & 27-Jan-12 & $9: 35: 04$ & $9: 45: 17$ & $0: 10: 13$ & 0 & 0 & $S$ \\
\hline 23 & 27-Jan-12 & 10:09:07 & $10: 31: 00$ & $0: 21: 53$ & 2 & 5 & $S$ \\
\hline 24 & 27-Jan-12 & $12: 57: 00$ & 13:07:31 & $0: 10: 31$ & 0 & 0 & $S$ \\
\hline 25 & 28-Jan-12 & $9: 15: 14$ & $9: 44: 23$ & 0:29:09 & 1 & 2 & $S$ \\
\hline 26 & 28-Jan-12 & 11:34:03 & $11: 44: 58$ & $0: 10: 55$ & 0 & 0 & $S$ \\
\hline 27 & 28-Jan-12 & $12: 54: 18$ & $13: 05: 47$ & $0: 11: 29$ & 0 & 0 & $S$ \\
\hline 28 & 28-Jan-12 & $13: 33: 31$ & $13: 44: 17$ & $0: 10: 46$ & 0 & 0 & $S$ \\
\hline 29 & 28-Jan-12 & 14:09:34 & $14: 22: 42$ & $0: 13: 08$ & 0 & 0 & $S$ \\
\hline 30 & 30-Jan-12 & $9: 23: 55$ & $9: 35: 26$ & $0: 11: 31$ & 0 & 0 & $S$ \\
\hline 31 & 30-Jan-12 & $10: 34: 50$ & $10: 56: 01$ & $0: 21: 11$ & 0 & 0 & $S$ \\
\hline 32 & 30-Jan-12 & $13: 43: 46$ & $13: 55: 16$ & $0: 11: 30$ & 0 & 0 & $S$ \\
\hline 33 & 30-Jan-12 & 14:18:00 & $14: 33: 00$ & $0: 15: 00$ & 0 & 0 & $S$ \\
\hline 34 & 31-Jan-12 & $8: 59: 00$ & $9: 26: 00$ & $0: 27: 00$ & 1 & 1 & $S$ \\
\hline 35 & 31-Jan-12 & $9: 56: 00$ & 10:07:00 & 0:11:00 & 0 & 0 & $S$ \\
\hline 36 & 31-Jan-12 & $10: 54: 00$ & 11:09:00 & $0: 15: 00$ & 0 & 0 & $S$ \\
\hline 37 & 31-Jan-12 & $12: 12: 42$ & $12: 23: 31$ & $0: 10: 49$ & 0 & 0 & $\mathrm{~S}$ \\
\hline 38 & 31-Jan-12 & 13:39:03 & $13: 52: 24$ & $0: 13: 21$ & 0 & 0 & $S$ \\
\hline 39 & 01-Feb-12 & $10: 38: 14$ & $10: 48: 13$ & 0:09:59 & 0 & 0 & $S$ \\
\hline 40 & 02-Feb-12 & $9: 11: 30$ & $9: 22: 20$ & $0: 10: 50$ & 0 & 0 & $\mathrm{~S}$ \\
\hline 41 & 02-Feb-12 & $11: 17: 49$ & $11: 36: 45$ & $0: 18: 56$ & 2 & 2 & $S$ \\
\hline 42 & 02-Feb-12 & $12: 22: 01$ & $12: 39: 45$ & $0: 17: 44$ & 1 & 1 & $S$ \\
\hline 43 & 02-Feb-12 & $13: 12: 51$ & $13: 30: 09$ & $0: 17: 18$ & 1 & 2 & $S$ \\
\hline
\end{tabular}




\begin{tabular}{|c|c|c|c|c|c|c|c|}
\hline Scan & Date & $\begin{array}{l}\text { Start } \\
\text { Time }\end{array}$ & $\begin{array}{l}\text { End } \\
\text { Time }\end{array}$ & $\begin{array}{l}\text { Duration } \\
\text { (h:m:s) }\end{array}$ & $\begin{array}{l}\text { Number of } \\
\text { whales/whale } \\
\text { groups }\end{array}$ & $\begin{array}{l}\text { Total } \\
\text { number } \\
\text { of whales }\end{array}$ & $\begin{array}{l}\text { Migration } \\
\text { Heading }\end{array}$ \\
\hline 44 & 03-Feb-12 & $13: 11: 25$ & $13: 22: 16$ & $0: 10: 51$ & 0 & 0 & $S$ \\
\hline 45 & 03-Feb-12 & $14: 02: 30$ & $14: 15: 14$ & $0: 12: 44$ & 0 & 0 & $S$ \\
\hline 46 & 05-Feb-12 & 9:01:51 & $9: 13: 00$ & 0:11:09 & 0 & 0 & $S$ \\
\hline 47 & 05-Feb-12 & $10: 05: 53$ & $10: 26: 47$ & $0: 20: 54$ & 1 & 1 & $S$ \\
\hline 48 & 05-Feb-12 & 13:39:40 & $13: 49: 44$ & 0:10:04 & 0 & 0 & $S$ \\
\hline 49 & 09-Feb-12 & $12: 43: 33$ & $12: 54: 19$ & $0: 10: 46$ & 0 & 0 & $S$ \\
\hline 50 & 09-Feb-12 & $13: 37: 12$ & $13: 48: 25$ & $0: 11: 13$ & 0 & 0 & $S$ \\
\hline 51 & 11-Feb-12 & 10:38:35 & 10:49:41 & 0:11:06 & 0 & 0 & $S$ \\
\hline 52 & 11-Feb-12 & $11: 42: 47$ & $11: 52: 53$ & 0:10:06 & 0 & 0 & $S$ \\
\hline 53 & 11-Feb-12 & $12: 53: 11$ & 13:04:11 & 0:11:00 & 0 & 0 & $S$ \\
\hline 54 & 11-Feb-12 & $13: 38: 42$ & $13: 49: 31$ & $0: 10: 49$ & 0 & 0 & $S$ \\
\hline 55 & $15-F e b-12$ & $9: 48: 38$ & $9: 58: 28$ & 0:09:50 & 0 & 0 & $S$ \\
\hline 56 & 15-Feb-12 & 10:49:37 & $11: 00: 34$ & $0: 10: 57$ & 0 & 0 & $S$ \\
\hline 57 & $15-F e b-12$ & $11: 50: 50$ & $12: 02: 02$ & $0: 11: 12$ & 0 & 0 & $S$ \\
\hline 58 & 15-Feb-12 & $13: 12: 16$ & $13: 27: 00$ & $0: 14: 44$ & 0 & 0 & $S$ \\
\hline 59 & 15-Feb-12 & $14: 54: 20$ & $15: 05: 49$ & $0: 11: 29$ & 0 & 0 & $S$ \\
\hline 60 & 19-Feb-12 & $9: 31: 37$ & $9: 46: 04$ & $0: 14: 27$ & 0 & 0 & $\mathrm{~N}$ \\
\hline 61 & 19-Feb-12 & $10: 31: 35$ & 10:42:09 & $0: 10: 34$ & 0 & 0 & $\mathrm{~N}$ \\
\hline 62 & 19-Feb-12 & $11: 30: 36$ & $11: 43: 54$ & $0: 13: 18$ & 0 & 0 & $\mathrm{~N}$ \\
\hline 63 & 19-Feb-12 & $14: 16: 31$ & $14: 26: 24$ & 0:09:53 & 0 & 0 & $\mathrm{~N}$ \\
\hline 64 & 23-Feb-12 & $11: 33: 26$ & $11: 43: 32$ & 0:10:06 & 0 & 0 & $\mathrm{~N}$ \\
\hline 65 & 23-Feb-12 & $12: 28: 38$ & $12: 39: 18$ & $0: 10: 40$ & 0 & 0 & $\mathrm{~N}$ \\
\hline 66 & 23-Feb-12 & 13:14:03 & $13: 24: 38$ & $0: 10: 35$ & 0 & 0 & $\mathrm{~N}$ \\
\hline
\end{tabular}




\begin{tabular}{|c|c|c|c|c|c|c|c|}
\hline Scan & Date & $\begin{array}{l}\text { Start } \\
\text { Time }\end{array}$ & $\begin{array}{l}\text { End } \\
\text { Time }\end{array}$ & $\begin{array}{l}\text { Duration } \\
\text { (h:m:s) }\end{array}$ & $\begin{array}{l}\text { Number of } \\
\text { whales/whale } \\
\text { groups }\end{array}$ & $\begin{array}{l}\text { Total } \\
\text { number } \\
\text { of whales }\end{array}$ & $\begin{array}{l}\text { Migration } \\
\text { Heading }\end{array}$ \\
\hline 67 & 23-Feb-12 & 14:06:55 & $14: 18: 38$ & $0: 11: 43$ & 0 & 0 & $\mathrm{~N}$ \\
\hline 68 & 24-Feb-12 & $10: 38: 34$ & 10:49:32 & $0: 10: 58$ & 0 & 0 & $\mathrm{~N}$ \\
\hline 69 & 27-Feb-12 & $9: 22: 29$ & $9: 35: 26$ & $0: 12: 57$ & 0 & 0 & $\mathrm{~N}$ \\
\hline 70 & 27-Feb-12 & 10:06:28 & $10: 17: 02$ & $0: 10: 34$ & 0 & 0 & $\mathrm{~N}$ \\
\hline 71 & 27-Feb-12 & $11: 25: 20$ & 11:58:01 & $0: 32: 41$ & 1 & 4 & $\mathrm{~N}$ \\
\hline 72 & 27-Feb-12 & $14: 18: 20$ & 14:39:30 & $0: 21: 10$ & 1 & 5 & $N$ \\
\hline 73 & 27-Feb-12 & $14: 51: 51$ & $15: 04: 10$ & $0: 12: 19$ & 0 & 0 & $\mathrm{~N}$ \\
\hline 74 & 01-Mar-12 & $12: 31: 55$ & $12: 43: 35$ & $0: 11: 40$ & 0 & 0 & $\mathrm{~N}$ \\
\hline 75 & 01-Mar-12 & 14:55:09 & $15: 20: 32$ & $0: 25: 23$ & 1 & 2 & $\mathrm{~N}$ \\
\hline 76 & 01-Mar-12 & $15: 44: 18$ & $16: 15: 37$ & 0:31:19 & 2 & 3 & $\mathrm{~N}$ \\
\hline 77 & 02-Mar-12 & $10: 15: 58$ & $10: 34: 47$ & $0: 18: 49$ & 0 & 0 & $N$ \\
\hline 78 & 02-Mar-12 & $10: 51: 40$ & $11: 12: 01$ & $0: 20: 21$ & 1 & 2 & $\mathrm{~N}$ \\
\hline 79 & 02-Mar-12 & 12:00:03 & $12: 29: 50$ & $0: 29: 47$ & 1 & 4 & $\mathrm{~N}$ \\
\hline 80 & 02-Mar-12 & $14: 03: 23$ & $14: 54: 32$ & 0:51:09 & 0 & 0 & $\mathrm{~N}$ \\
\hline 81 & 03-Mar-12 & $12: 04: 52$ & $12: 25: 00$ & 0:20:08 & 0 & 0 & $\mathrm{~N}$ \\
\hline 82 & 03-Mar-12 & 14:09:54 & $14: 29: 32$ & $0: 19: 38$ & 0 & 0 & $\mathrm{~N}$ \\
\hline 83 & 03-Mar-12 & $15: 14: 47$ & $15: 34: 13$ & 0:19:26 & 0 & 0 & $\mathrm{~N}$ \\
\hline 84 & 04-Mar-12 & 10:30:04 & $10: 50: 20$ & $0: 20: 16$ & 0 & 0 & $N$ \\
\hline 85 & 04-Mar-12 & 11:29:39 & $11: 54: 49$ & $0: 25: 10$ & 1 & 2 & $\mathrm{~N}$ \\
\hline 86 & 04-Mar-12 & $15: 14: 27$ & $15: 49: 57$ & $0: 35: 30$ & 3 & 4 & $\mathrm{~N}$ \\
\hline 87 & 06-Mar-12 & $12: 43: 32$ & $13: 07: 12$ & $0: 23: 40$ & 0 & 0 & $N$ \\
\hline 88 & 07-Mar-12 & $10: 35: 46$ & $11: 07: 08$ & $0: 31: 22$ & 0 & 0 & $\mathrm{~N}$ \\
\hline 89 & 07-Mar-12 & $13: 43: 48$ & $14: 11: 16$ & $0: 27: 28$ & 2 & 2 & $\mathrm{~N}$ \\
\hline
\end{tabular}




\begin{tabular}{|c|c|c|c|c|c|c|c|}
\hline Scan & Date & $\begin{array}{l}\text { Start } \\
\text { Time }\end{array}$ & $\begin{array}{l}\text { End } \\
\text { Time }\end{array}$ & $\begin{array}{l}\text { Duration } \\
\text { (h:m:s) }\end{array}$ & $\begin{array}{l}\text { Number of } \\
\text { whales/whale } \\
\text { groups }\end{array}$ & $\begin{array}{l}\text { Total } \\
\text { number } \\
\text { of whales }\end{array}$ & $\begin{array}{l}\text { Migration } \\
\text { Heading }\end{array}$ \\
\hline 90 & 08-Mar-12 & $8: 57: 11$ & $9: 41: 39$ & $0: 44: 28$ & 3 & 3 & $\mathrm{~N}$ \\
\hline 91 & 08-Mar-12 & $10: 24: 18$ & $11: 02: 57$ & 0:38:39 & 1 & 1 & $\mathrm{~N}$ \\
\hline 92 & 08-Mar-12 & $11: 32: 50$ & $12: 39: 05$ & 1:06:15 & 3 & 7 & $\mathrm{~N}$ \\
\hline 93 & 16-Mar-12 & 10:00:39 & $10: 27: 36$ & $0: 26: 57$ & 1 & 1 & $\mathrm{~N}$ \\
\hline 94 & 18-Mar-12 & $11: 12: 22$ & $11: 52: 33$ & $0: 40: 11$ & 3 & 4 & $\mathrm{~N}$ \\
\hline 95 & 19-Mar-12 & $9: 06: 00$ & $9: 38: 25$ & $0: 32: 25$ & 1 & 2 & $\mathrm{~N}$ \\
\hline 96 & 19-Mar-12 & $10: 51: 44$ & $11: 11: 34$ & 0:19:50 & 0 & 0 & $\mathrm{~N}$ \\
\hline 97 & 22-Mar-12 & $10: 43: 47$ & $11: 02: 22$ & $0: 18: 35$ & 0 & 0 & $E$ \\
\hline 98 & 22-Mar-12 & 11:39:44 & $12: 09: 08$ & $0: 29: 24$ & 1 & 3 & $\mathrm{~N}$ \\
\hline 99 & 22-Mar-12 & $13: 02: 26$ & 13:19:02 & $0: 16: 36$ & 3 & 4 & $\mathrm{~N}$ \\
\hline 100 & 23-Mar-12 & $9: 20: 43$ & $9: 43: 30$ & $0: 22: 47$ & 1 & 2 & $\mathrm{~N}$ \\
\hline 101 & 23-Mar-12 & $10: 11: 22$ & $10: 36: 52$ & $0: 25: 30$ & 1 & 1 & $\mathrm{~N}$ \\
\hline 102 & 23-Mar-12 & $11: 31: 54$ & 11:59:09 & $0: 27: 15$ & 2 & 3 & $\mathrm{~N}$ \\
\hline 103 & 23-Mar-12 & $13: 50: 23$ & $14: 14: 37$ & $0: 24: 14$ & 2 & 2 & $\mathrm{~N}$ \\
\hline 104 & 24-Mar-12 & $9: 20: 21$ & $10: 24: 44$ & 1:04:23 & 4 & 6 & $\mathrm{~N}$ \\
\hline 105 & 25-Mar-12 & 9:04:17 & $9: 43: 09$ & $0: 38: 52$ & 1 & 3 & $\mathrm{~N}$ \\
\hline 106 & 25-Mar-12 & $10: 21: 57$ & $10: 42: 42$ & $0: 20: 45$ & 0 & 0 & $\mathrm{~N}$ \\
\hline 107 & 25-Mar-12 & $11: 16: 42$ & $11: 54: 18$ & $0: 37: 36$ & 1 & 1 & $\mathrm{~N}$ \\
\hline 108 & 03-Apr-12 & $12: 59: 43$ & $14: 04: 25$ & 1:04:42 & 1 & 1 & $\mathrm{~N}$ \\
\hline 109 & 05-Apr-12 & 9:17:07 & $9: 56: 21$ & 0:39:14 & 0 & 0 & $\mathrm{~N}$ \\
\hline 110 & $05-A p r-12$ & $12: 11: 51$ & $12: 37: 17$ & $0: 25: 26$ & 2 & 4 & $\mathrm{~N}$ \\
\hline 111 & $05-A p r-12$ & $13: 28: 29$ & $14: 00: 34$ & $0: 32: 05$ & 1 & 1 & $\mathrm{~N}$ \\
\hline 112 & 06-Apr-12 & $9: 16: 59$ & $9: 41: 29$ & $0: 24: 30$ & 2 & 3 & $\mathrm{~N}$ \\
\hline
\end{tabular}




\begin{tabular}{|c|c|c|c|c|c|c|c|}
\hline Scan & Date & $\begin{array}{l}\text { Start } \\
\text { Time }\end{array}$ & $\begin{array}{l}\text { End } \\
\text { Time }\end{array}$ & $\begin{array}{l}\text { Duration } \\
\text { (h:m:s) }\end{array}$ & $\begin{array}{l}\text { Number of } \\
\text { whales/whale } \\
\text { groups }\end{array}$ & $\begin{array}{l}\text { Total } \\
\text { number } \\
\text { of whales }\end{array}$ & $\begin{array}{l}\text { Migration } \\
\text { Heading }\end{array}$ \\
\hline 113 & 06-Apr-12 & $12: 45: 59$ & $13: 08: 33$ & $0: 22: 34$ & 2 & 3 & $\mathrm{~N}$ \\
\hline 114 & 07-Apr-12 & $9: 17: 21$ & $9: 40: 37$ & $0: 23: 16$ & 1 & 4 & $\mathrm{~N}$ \\
\hline 115 & 07-Apr-12 & $10: 37: 13$ & $11: 23: 39$ & $0: 46: 26$ & 3 & 4 & $\mathrm{~N}$ \\
\hline 116 & 07-Apr-12 & $12: 03: 32$ & $12: 23: 07$ & 0:19:35 & 0 & 0 & $\mathrm{~N}$ \\
\hline 117 & 07-Apr-12 & $15: 01: 13$ & $15: 28: 25$ & $0: 27: 12$ & 2 & 2 & $\mathrm{~N}$ \\
\hline 118 & $08-A p r-12$ & $12: 39: 30$ & $12: 57: 30$ & $0: 18: 00$ & 0 & 0 & $\mathrm{~N}$ \\
\hline 119 & 08-Apr-12 & $13: 54: 49$ & $14: 13: 21$ & $0: 18: 32$ & 0 & 0 & $\mathrm{~N}$ \\
\hline 120 & 08-Apr-12 & $14: 56: 44$ & $15: 23: 12$ & $0: 26: 28$ & 1 & 2 & $\mathrm{~N}$ \\
\hline 121 & 09-Apr-12 & 10:02:39 & $10: 23: 59$ & $0: 21: 20$ & 0 & 0 & $\mathrm{~N}$ \\
\hline 122 & 09-Apr-12 & $10: 53: 21$ & $11: 14: 07$ & $0: 20: 46$ & 0 & 0 & $\mathrm{~N}$ \\
\hline 123 & 09-Apr-12 & 12:09:39 & $12: 28: 21$ & $0: 18: 42$ & 0 & 0 & $\mathrm{~N}$ \\
\hline 124 & 09-Apr-12 & 14:10:19 & $14: 47: 20$ & $0: 37: 01$ & 0 & 0 & $\mathrm{~N}$ \\
\hline 125 & 10-Apr-12 & $9: 47: 24$ & $10: 10: 48$ & $0: 23: 24$ & 1 & 3 & $\mathrm{~N}$ \\
\hline 126 & 10-Apr-12 & $10: 48: 04$ & $11: 10: 11$ & $0: 22: 07$ & 0 & 0 & $\mathrm{~N}$ \\
\hline 127 & 11-Apr-12 & $9: 50: 36$ & $10: 23: 27$ & $0: 32: 51$ & 2 & 4 & $\mathrm{~N}$ \\
\hline 128 & $13-A p r-12$ & $10: 21: 34$ & $11: 08: 57$ & $0: 47: 23$ & 1 & 3 & $\mathrm{~N}$ \\
\hline 129 & 13-Apr-12 & $11: 51: 29$ & $12: 15: 40$ & $0: 24: 11$ & 0 & 0 & $\mathrm{~N}$ \\
\hline 130 & 13-Apr-12 & $13: 27: 58$ & $13: 55: 38$ & $0: 27: 40$ & 1 & 1 & $\mathrm{~N}$ \\
\hline 131 & $13-A p r-12$ & $15: 25: 25$ & $15: 49: 42$ & $0: 24: 17$ & 1 & 1 & $\mathrm{~N}$ \\
\hline 132 & 14-Apr-12 & $9: 37: 52$ & $10: 00: 28$ & $0: 22: 36$ & 0 & 0 & $\mathrm{~N}$ \\
\hline 133 & 14-Apr-12 & $12: 04: 25$ & $12: 23: 07$ & $0: 18: 42$ & 0 & 0 & $\mathrm{~N}$ \\
\hline 134 & 14-Apr-12 & $13: 50: 07$ & $14: 24: 56$ & $0: 34: 49$ & 2 & 2 & $\mathrm{~N}$ \\
\hline 135 & 15-Apr-12 & $9: 40: 56$ & 10:08:35 & $0: 27: 39$ & 0 & 0 & $\mathrm{~N}$ \\
\hline
\end{tabular}




\begin{tabular}{lllllllll}
\hline Scan & Date & $\begin{array}{l}\text { Start } \\
\text { Time }\end{array}$ & $\begin{array}{l}\text { End } \\
\text { Time }\end{array}$ & $\begin{array}{l}\text { Duration } \\
\text { (h:m:s) }\end{array}$ & $\begin{array}{l}\text { Number of } \\
\text { whales/whale } \\
\text { groups }\end{array}$ & $\begin{array}{l}\text { Total } \\
\text { number } \\
\text { of whales }\end{array}$ & $\begin{array}{l}\text { Migration } \\
\text { Heading }\end{array}$ \\
\hline 136 & $15-$ Apr-12 & $12: 32: 50$ & $12: 57: 08$ & $0: 24: 18$ & 1 & 1 & $\mathrm{~N}$ \\
137 & $15-$ Apr-12 & $14: 12: 12$ & $15: 10: 05$ & $0: 57: 53$ & 5 & 6 & $\mathrm{~N}$ \\
\hline
\end{tabular}




\section{Appendix II}

Table 1. Focal follow sampling events obtained during shore-based observations of migrating gray whales at Yaquina Head, Oregon, from January 3 -April 15, 2012, detailing number of whales, track length, speed, distance to shore, and average depth.

\begin{tabular}{|c|c|c|c|c|c|c|c|c|c|c|}
\hline Track \# & Start Date & Start Time & $\begin{array}{l}\text { Group } \\
\text { Size }\end{array}$ & $\begin{array}{l}\text { Duration } \\
\text { (h:m:s) }\end{array}$ & $\begin{array}{l}\# \quad \text { of } \\
\text { Fixes }\end{array}$ & $\begin{array}{l}\text { Track } \\
\text { Length } \\
(\mathrm{km})\end{array}$ & $\begin{array}{l}\text { Track Speed } \\
(\mathrm{km} / \mathrm{h})\end{array}$ & $\begin{array}{l}\text { Average } \\
\text { Distance to } \\
\text { Shore }(\mathrm{km})\end{array}$ & $\begin{array}{l}\text { Average } \\
\text { Depth }(\mathrm{m})\end{array}$ & $\begin{array}{l}\text { Migration } \\
\text { Heading }\end{array}$ \\
\hline 1 & 3-Jan-12 & $11: 18: 05$ & 1 & $0: 46: 53$ & 9 & 7.5 & 9.6 & 7.4 & 56 & $\mathrm{~S}$ \\
\hline 2 & 7-Jan-12 & $15: 05: 22$ & 1 & $0: 29: 40$ & 7 & 3.7 & 7.5 & 6.3 & 51 & $S$ \\
\hline 3 & 11-Jan-12 & $12: 50: 40$ & 9 & 1:48:02 & 17 & 19.1 & 10.6 & 12.4 & 74 & $S$ \\
\hline 4 & 12-Jan-12 & $11: 53: 21$ & 4 & 1:38:10 & 16 & 7.4 & 4.5 & 3.3 & 38 & $S$ \\
\hline 5 & 12-Jan-12 & $12: 23: 23$ & 1 & $0: 20: 35$ & 5 & 3.1 & 8.9 & 7.5 & 60 & $S$ \\
\hline 6 & 13-Jan-12 & 10:29:05 & 5 & 1:46:14 & 14 & 11.5 & 6.5 & 7.9 & 61 & $S$ \\
\hline 7 & 13-Jan-12 & $13: 41: 23$ & 1 & $0: 32: 37$ & 8 & 3.7 & 6.8 & 2.8 & 40 & $S$ \\
\hline 8 & 27-Jan-12 & $10: 47: 32$ & 2 & 1:06:22 & 8 & 8.1 & 7.4 & 8.6 & 66 & $\mathrm{~S}$ \\
\hline 9 & 27-Jan-12 & $12: 02: 29$ & 1 & $0: 47: 47$ & 4 & 6.3 & 7.9 & 12.3 & 70 & $\mathrm{~S}$ \\
\hline 10 & 28-Jan-12 & $10: 04: 20$ & 2 & 0:19:43 & 3 & 1.8 & 5.6 & 7.3 & 60 & $\mathrm{~S}$ \\
\hline 11 & 28-Jan-12 & $14: 59: 16$ & 2 & $1: 31: 50$ & 22 & 15.0 & 9.8 & 7.9 & 63 & $S$ \\
\hline 12 & 30-Jan-12 & $10: 00: 21$ & 2 & $0: 15: 14$ & 3 & 1.5 & 6.1 & 0.8 & 15 & $S$ \\
\hline 13 & 30-Jan-12 & 11:04:15 & 2 & 0:32:00 & 6 & 4.2 & 7.9 & 6.7 & 61 & $S$ \\
\hline
\end{tabular}




\begin{tabular}{|c|c|c|c|c|c|c|c|c|c|c|}
\hline Track \# & Start Date & Start Time & $\begin{array}{l}\text { Group } \\
\text { Size }\end{array}$ & $\begin{array}{l}\text { Duration } \\
\text { (h:m:s) }\end{array}$ & $\begin{array}{l}\# \quad \text { of } \\
\text { Fixes }\end{array}$ & $\begin{array}{l}\text { Track } \\
\text { Length } \\
(\mathrm{km})\end{array}$ & $\begin{array}{l}\text { Track Speed } \\
(\mathrm{km} / \mathrm{h})\end{array}$ & $\begin{array}{l}\text { Average } \\
\text { Distance to } \\
\text { Shore }(\mathrm{km})\end{array}$ & $\begin{array}{l}\text { Average } \\
\text { Depth (m) }\end{array}$ & $\begin{array}{l}\text { Migration } \\
\text { Heading }\end{array}$ \\
\hline 14 & 30-Jan-12 & 11:11:41 & 4 & 2:02:58 & 8 & 10.1 & 4.9 & 6.7 & 51 & $\mathrm{~S}$ \\
\hline 15 & 31-Jan-12 & $12: 26: 59$ & 1 & 1:01:55 & 3 & 7.0 & 6.7 & 2.9 & 35 & $S$ \\
\hline 16 & 31-Jan-12 & 14:09:30 & 2 & 1:09:23 & 9 & 6.7 & 5.8 & 4.6 & 46 & $S$ \\
\hline 17 & 2-Feb-12 & $9: 33: 01$ & 1 & $0: 17: 41$ & 4 & 1.9 & 6.5 & 4.3 & 40 & $S$ \\
\hline 18 & 2-Feb-12 & $9: 53: 40$ & 2 & $0: 53: 42$ & 6 & 6.6 & 7.4 & 4.2 & 44 & $S$ \\
\hline 19 & 2-Feb-12 & $13: 32: 41$ & 2 & 2:20:03 & 18 & 16.8 & 7.2 & 4.6 & 47 & $S$ \\
\hline 20 & 5-Feb-12 & $10: 36: 56$ & 4 & $2: 36: 16$ & 18 & 17.4 & 6.7 & 7.6 & 58 & $\mathrm{~S}$ \\
\hline 21 & 5-Feb-12 & $13: 52: 08$ & 2 & 1:55:45 & 18 & 17.1 & 8.9 & 8.7 & 62 & $S$ \\
\hline 22 & $11-F e b-12$ & $13: 52: 48$ & 2 & 1:59:59 & 13 & 9.4 & 4.7 & 3.7 & 40 & $S$ \\
\hline 23 & $15-F e b-12$ & $14: 12: 07$ & 2 & $0: 27: 52$ & 6 & 3.1 & 6.6 & 8.0 & 53 & $S$ \\
\hline 24 & $15-F e b-12$ & $15: 34: 52$ & 2 & $0: 57: 38$ & 8 & 8.3 & 8.6 & 8.6 & 64 & $S$ \\
\hline 25 & 19-Feb-12 & $13: 26: 34$ & 1 & $0: 07: 32$ & 2 & 0.8 & 6.5 & 1.8 & 33 & $N$ \\
\hline 26 & 24-Feb-12 & $9: 53: 00$ & 4 & $0: 37: 15$ & 9 & 4.0 & 6.5 & 3.7 & 41 & $\mathrm{~N}$ \\
\hline 27 & 24-Feb-12 & 10:59:07 & 2 & $0: 41: 31$ & 5 & 3.8 & 5.4 & 2.3 & 26 & $\mathrm{~N}$ \\
\hline 28 & 27-Feb-12 & $10: 37: 14$ & 2 & $0: 36: 33$ & 5 & 4.0 & 6.6 & 2.5 & 35 & $\mathrm{~N}$ \\
\hline 29 & 27-Feb-12 & $12: 07: 25$ & 1 & $0: 21: 25$ & 5 & 2.4 & 6.8 & 5.7 & 47 & $N$ \\
\hline
\end{tabular}




\begin{tabular}{|c|c|c|c|c|c|c|c|c|c|c|}
\hline Track \# & Start Date & Start Time & $\begin{array}{l}\text { Group } \\
\text { Size }\end{array}$ & $\begin{array}{l}\text { Duration } \\
\text { (h:m:s) }\end{array}$ & $\begin{array}{l}\# \quad \text { of } \\
\text { Fixes }\end{array}$ & $\begin{array}{l}\text { Track } \\
\text { Length } \\
(\mathrm{km})\end{array}$ & $\begin{array}{l}\text { Track Speed } \\
(\mathrm{km} / \mathrm{h})\end{array}$ & $\begin{array}{l}\text { Average } \\
\text { Distance to } \\
\text { Shore }(\mathrm{km})\end{array}$ & $\begin{array}{l}\text { Average } \\
\text { Depth }(\mathrm{m})\end{array}$ & $\begin{array}{l}\text { Migration } \\
\text { Heading }\end{array}$ \\
\hline 30 & 27-Feb-12 & $12: 29: 40$ & 1 & $0: 41: 03$ & 4 & 4.2 & 6.1 & 3.4 & 44 & $\mathrm{~N}$ \\
\hline 31 & 27-Feb-12 & $13: 06: 22$ & 3 & $0: 44: 23$ & 6 & 4.7 & 6.3 & 10.4 & 68 & $N$ \\
\hline 32 & 1-Mar-12 & $13: 00: 21$ & 4 & 1:32:10 & 17 & 8.7 & 5.7 & 3.2 & 41 & $N$ \\
\hline 33 & 2-Mar-12 & 9:23:13 & 4 & 0:51:01 & 7 & 5.9 & 7.0 & 3.4 & 40 & $N$ \\
\hline 34 & 2-Mar-12 & $12: 57: 13$ & 2 & $0: 47: 33$ & 6 & 5.1 & 6.5 & 2.6 & 31 & $N$ \\
\hline 35 & 3-Mar-12 & $12: 44: 48$ & 3 & 0:18:43 & 3 & 2.0 & 6.4 & 2.8 & 40 & $N$ \\
\hline 36 & 4-Mar-12 & $12: 30: 34$ & 1 & $2: 39: 50$ & 5 & 13.5 & 5.1 & 5.7 & 50 & $N$ \\
\hline 37 & 7-Mar-12 & 8:58:34 & 4 & 1:18:48 & 24 & 10.8 & 8.2 & 3.4 & 41 & $N$ \\
\hline 38 & 7-Mar-12 & $11: 18: 26$ & 5 & 2:08:49 & 25 & 14.9 & 7.0 & 5.1 & 49 & $N$ \\
\hline 39 & 18-Mar-12 & $12: 01: 19$ & 2 & 0:05:47 & 2 & 0.3 & 3.6 & 9.0 & 55 & $N$ \\
\hline 40 & 18-Mar-12 & $12: 54: 55$ & 1 & 0:34:09 & 3 & 0.9 & 1.5 & 1.2 & 18 & $N$ \\
\hline 41 & 23-Mar-12 & $12: 21: 27$ & 1 & 1:02:07 & 16 & 6.4 & 6.2 & 3.2 & 40 & $N$ \\
\hline 42 & 23-Mar-12 & $14: 24: 14$ & 2 & 1:33:12 & 18 & 22.2 & 14.3 & 10.1 & 62 & $N$ \\
\hline 43 & 3-Apr-12 & $14: 21: 53$ & 4 & $1: 17: 47$ & 10 & 11.4 & 8.8 & 7.1 & 57 & $\mathrm{~N}$ \\
\hline 44 & 5-Apr-12 & $14: 16: 56$ & 3 & 1:40:41 & 15 & 12.8 & 7.6 & 7.4 & 58 & $N$ \\
\hline 45 & 6-Apr-12 & $10: 04: 34$ & 3 & $1: 57: 06$ & 10 & 15.2 & 7.8 & 9.0 & 63 & $N$ \\
\hline
\end{tabular}




\begin{tabular}{|c|c|c|c|c|c|c|c|c|c|c|}
\hline Track \# & Start Date & Start Time & $\begin{array}{l}\text { Group } \\
\text { Size }\end{array}$ & $\begin{array}{l}\text { Duration } \\
\text { (h:m:s) }\end{array}$ & $\begin{array}{l}\text { \# of } \\
\text { Fixes }\end{array}$ & $\begin{array}{l}\text { Track } \\
\text { Length } \\
(\mathrm{km})\end{array}$ & $\begin{array}{l}\text { Track Speed } \\
(\mathrm{km} / \mathrm{h})\end{array}$ & $\begin{array}{l}\text { Average } \\
\text { Distance to } \\
\text { Shore }(\mathrm{km})\end{array}$ & $\begin{array}{l}\text { Average } \\
\text { Depth }(\mathrm{m})\end{array}$ & $\begin{array}{l}\text { Migration } \\
\text { Heading }\end{array}$ \\
\hline 46 & 6-Apr-12 & $13: 39: 10$ & 2 & $0: 50: 39$ & 4 & 5.5 & 6.5 & 12.2 & 71 & $\mathrm{~N}$ \\
\hline 47 & 6-Apr-12 & $14: 15: 36$ & 2 & 1:08:44 & 9 & 7.2 & 6.2 & 5.0 & 49 & $\mathrm{~N}$ \\
\hline 48 & 7-Apr-12 & $12: 58: 22$ & 1 & 1:49:19 & 10 & 10.0 & 5.5 & 5.9 & 53 & $\mathrm{~N}$ \\
\hline 49 & 9-Apr-12 & 13:01:09 & 4 & $0: 31: 45$ & 6 & 2.7 & 5.1 & 1.7 & 28 & $\mathrm{~N}$ \\
\hline 50 & 9-Apr-12 & 13:39:17 & 2 & $0: 29: 16$ & 7 & 2.9 & 5.9 & 2.8 & 39 & $\mathrm{~N}$ \\
\hline 51 & 10-Apr-12 & $11: 27: 39$ & 5 & 2:14:43 & 20 & 17.3 & 7.7 & 9.3 & 63 & $\mathrm{~N}$ \\
\hline 52 & 11-Apr-12 & 10:39:37 & 4 & 1:39:15 & 15 & 16.8 & 10.2 & 9.6 & 63 & $\mathrm{~N}$ \\
\hline 53 & 13-Apr-12 & $14: 16: 42$ & 2 & $0: 55: 02$ & 12 & 6.0 & 6.5 & 3.7 & 44 & $\mathrm{~N}$ \\
\hline 54 & 14-Apr-12 & 10:20:59 & 4 & 1:08:53 & 9 & 8.7 & 7.6 & 4.9 & 49 & $\mathrm{~N}$ \\
\hline 55 & 14-Apr-12 & $15: 30: 29$ & 1 & 1:31:37 & 9 & 11.1 & 7.2 & 5.2 & 49 & $\mathrm{~N}$ \\
\hline 56 & $15-A p r-12$ & $10: 27: 31$ & 2 & 1:33:05 & 13 & 11.8 & 7.6 & 9.1 & 63 & $N$ \\
\hline 57 & $15-A p r-12$ & $13: 22: 09$ & 1 & $0: 11: 44$ & 2 & 1.7 & 8.8 & 5.2 & 43 & $\mathrm{~N}$ \\
\hline
\end{tabular}


Appendix III: Final Technical Report 


\section{Final Technical Report}

\section{Active Acoustic Deterrence of Migratory Whales}

$6 / 21 / 2013$

This project was funded by the U.S. Department of Energy, through an award to Pacific Energy Ventures LLC (Award Number DE-EE0002660). This work was also supported in part by the Oregon Wave Energy Trust, the Northwest National Marine Renewable Energy Center, and Oregon State University's Marine Mammal Endowment. The U.S. Bureau of Land Management's Yaquina Head Outstanding Natural Area provided logistical support and access to the deck in front of Yaquina Head Lighthouse for project observations. 


\section{Contents}

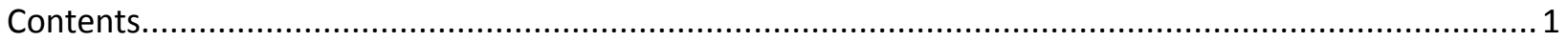

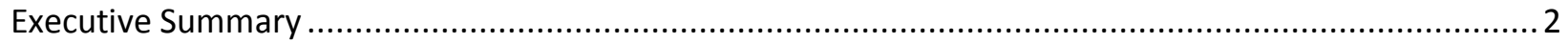

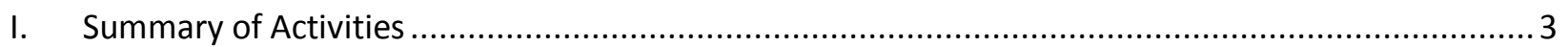

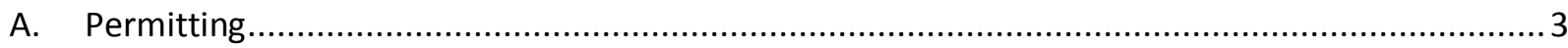

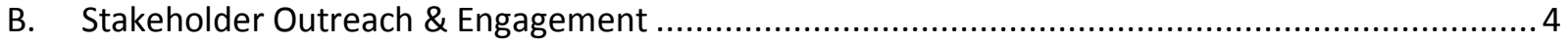

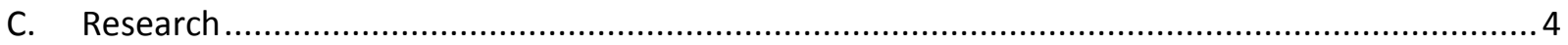

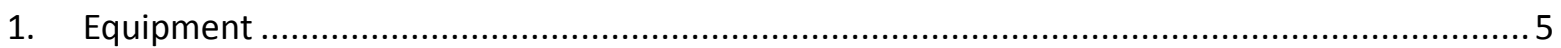

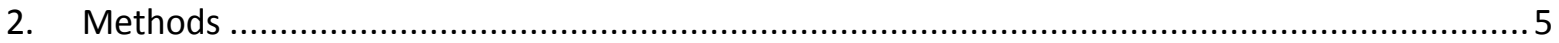

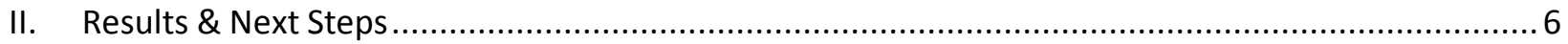

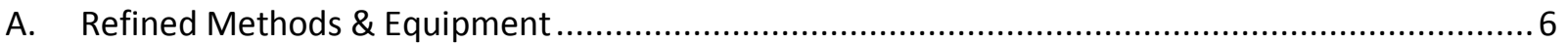

III. Comparison of Actual Accomplishments with Goals \& Objectives ........................................ 7

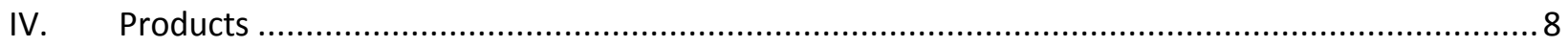

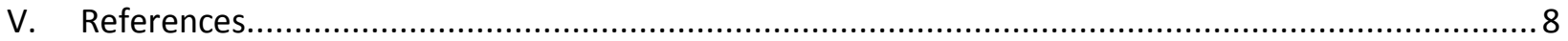

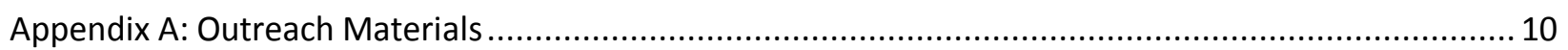

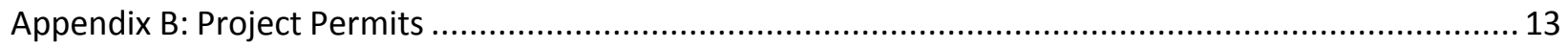




\section{Executive Summary}

The purpose of this project was to evaluate the effectiveness of an acoustic deterrent mechanism in deflecting migratory gray whales around marine and hydrokinetic (MHK) energy facilities. With increased interest in MHK development along the Oregon coast, there is some concern that such facilities may pose a collision or entanglement risk for gray whales. Multiple scientific reports have identified collision and entanglement as potential risks to marine mammals (Gill 2005, Wilson et al. 2007, Boehlert et al. 2008, Ortega-Ortiz and Lagerquist 2008, Dolman and Simmonds 2010); if it is found that MHK structures pose collision and/or entanglement risks to migratory whales, such acoustic deterrent mechanisms could be utilized to mitigate these risks.

The Project Team consisted of Pacific Energy Ventures (PEV) and the Oregon State University's Marine Mammal Institute (OSUMMI). The project involved designing, fabricating and deploying an active acoustic deterrence device off the coast of Oregon and conducting monitoring to determine the behavioral response of migrating grey whales. The project also involved securing state and federal permits and approvals to authorize deployment of the active acoustic device, as well as engaging with marine mammal researchers, the MHK industry, and members of the public.

The acoustic deterrence device was deployed in the pathway of migrating gray whales off Yaquina Head on the central Oregon coast. Shore-based observers, who did not know when the device was transmitting, used a theodolite to track whales as they passed the headland. Individual locations of different whales and groups of whales, as well as tracklines of the same whales/whale groups, were obtained and compared between times when the acoustic device was transmitting (experimental period) and when it was off (control period). The study results were analyzed and a scientific report on the behavioral response of gray whales to the acoustic signal was prepared.

Results of the 2012 study suggest that the acoustic deterrent device was not effective in achieving the hypothesized zone of influence. Inclement weather and equipment problems resulted in very small sample sizes, however, especially when the deterrent was transmitting. Due to the inadequate sample, the 2012 results are inconclusive. However, the Project Team has applied the experienced gained from this project to refine the hypothesis, optimize study methods and modify equipment. Another season of field testing, with support from other public and private sources, commenced in January 2013, and the Project Team is confident that with these improvements, they will be able make a confident determination as to whether the acoustic deterrent system is effective at deflecting gray whales. The results of the 2013 observations will be published in publicly available literature by September 2013. Initial results indicate that the device was effective.

While technical and process issues presented significant challenges, the project ultimately resulted in improved methodologies and equipment for the acoustic deterrence system. Through the efforts required to address and overcome these issues, the study design was optimized to successfully investigate the effectiveness of this type of system in mitigating potential risks associated with whale entanglement in MHK facilities. By informing mitigation measures to facilitate MHK siting and development, this project helps advance MHK development and support the U.S. Department of 
Energy's mission and objective to accelerate development of clean, affordable energy generation that is economically viable and environmentally responsible.

\section{Summary of Activities}

This project involved deploying an active acoustic device off the coast of Yaquina Head, OR and measuring the behavioral response of migrating gray whales to evaluate the effectiveness of an acoustic deterrent mechanism in deflecting migratory gray whales. The project tasks consisted of three primary efforts: Permitting, Stakeholder Outreach \& Engagement, and Research, which are summarized in the sections that follow.

\section{A. Permitting}

Project permitting was led by PEV and conducted in coordination with OSUMMI. In December 2009, the U.S. Department of Energy (DOE) award to PEV was executed and the subcontract agreement with OSUMMI was finalized and signed. The contract from DOE was not received until December 21, 2009, however, which precluded PEV from issuing a subcontract to OSUMMI to start the research. Once the contractual agreements were in place, the Project Team started coordinating with resource and regulatory agencies to initiate the permitting process.

Because the research involved using an active acoustic signal designed to alter the migration path of gray whales, the project required authorization from the National Marine Fisheries Service (NMFS) under the Marine Mammal Protection Act (MMPA) and the Endangered Species Act (ESA). NMFS initially indicated that the MMPA permit could be issued with a General Authorization. In midDecember 2009, however, the Project Team learned that NMFS had concluded that the project required a full Incidental Harassment Authorization (IHA) and an Environmental Assessment (EA). The Project Team developed a permit application to authorize take of marine mammals by level B harassment. In addition, an EA was prepared analyzing the full scope of the project's potential environmental effects. Based on the analyses in the EA, NMFS determined that issuance of the permit would not significantly impact the quality of the environment. That determination was documented in a Finding of No Significant Impact (FONSI), signed on October 29, 2010, and NMFS issued the IHA on November 8, 2010 (Permit No. 15483).

Because the acoustic device was temporarily moored to the seabed, a Nationwide Permit (NWP) from the U.S. Army Corps of Engineers (the Corps) was also required. During the initial reporting period, PEV consulted with the Corps and prepared the permit application, which was issued on October 26, 2010 (NWP-2010-385). Similarly, authorization from the Oregon Department of State Lands (DSL) was required for use of state submerged lands where the device was deployed. DSL issued a Short Term Access Agreement for the project on September 20, 2010. Approval from the U.S. Coast Guard was also obtained for the surface buoy and associated navigational aids for the instrumentation system. Copies of the permits issued for the project are included in Appendix B of this report.

As noted above, the original project timeframes were based on the DOE contract award being made in September 2009 and active research commencing in mid-December 2009 (to coincide with the start of 
the southbound whale migration). In addition, the NMFS permitting process was several months longer than anticipated, so the project permits were not effectively in place until NMFS issued its authorization in November 2010. As a result of these process delays, the start of the active research was postponed until January $2011 .^{1}$

\section{B. Stakeholder Outreach \& Engagement}

In conjunction with the permitting process, the Project Team designed and implemented a stakeholder outreach and engagement strategy. First, Project Team engaged with coastal stakeholders to communicate the intent of the project and to alleviate concerns regarding incidental harassment of mammals as a result of the research. The Project Team developed detailed information sheets about the project and convened a town hall meeting in Newport, OR on May 12, 2010. ${ }^{2}$ The purpose of the meeting was to inform local residents and interested parties about the study and to provide an opportunity to address any questions or concerns. An overview of the study was presented, along with the informational outreach materials. After the presentation, Dr. Bruce Mate, Director of the OSUMMI and head project researcher, answered questions about the study.

In addition to public outreach, the Project Team convened a meeting between marine mammal researchers and MHK technology developers to determine specific information needs and data requirements. Utilizing input from that meeting, the Project Team designed and fabricated a prototype active acoustic deterrence device and instrumentation system. Following the acoustic device deployment and monitoring in 2012, the results were widely disseminated to inform stakeholders of the initial study results. In addition, OSUMMI researchers prepared a scientific report, Testing the effectiveness of an acoustic deterrent for gray whales along the Oregon coast, documenting behavioral response to the acoustic signal (Lagerquist, et. Al 2012).

\section{Research}

The majority of the research task was completed by OSUMMI at the Hatfield Marine Science Center. Integration with other programs, like the Northwest National Marine Renewable Energy Center and the Oregon Wave Energy Trust gray whale baseline studies, further leveraged this research. The original study hypothesis was that an active acoustic signal would deflect migrating gray whales away from the acoustic deterrent device. Specifically, the researchers hypothesized that the number of gray whale observed within $500 \mathrm{~m}$ of the acoustic device would be $50 \%$ lower during experimental periods (active sound production) than during control periods (no sound production).

To test that hypothesis, a prototype acoustic deterrence device was moored on the seafloor in the pathway of migrating gray whales off the coast of Yaquina Head, Oregon. The research team documented the device's acoustic signature at varying distances from the source, while shore-based observers stationed near the base of the Yaquina Head lighthouse used an integrated system of

\footnotetext{
${ }^{1}$ A request for an extension of the contract was submitted to and approved by DOE in 2010.

${ }^{2}$ Copies of this information sheet and other outreach materials were provided to DOE during the quarterly reporting periods, and general outreach materials are included in Appendix A of this report.
} 
binoculars, theodolites, and proprietary computer software to track whale movement. The observers recorded gray whale locations during both experiment and control periods, but the observers did not know when the device was transmitting the acoustic signal. The observations of whale locations during the experimental period (times that the acoustic device was transmitting) were then compared with observations taken during the control period (when the device was off) to determine whether there was a behavioral response from the whales.

\section{Equipment}

The primary components of the prototype deterrent system developed for this study include an acoustic signal generator connected to four batteries, which were installed separately in waterproof/pressureproof housings (one for the signal generator and two for the batteries). As discussed in the scientific report, a source level of $170 \mathrm{~dB}$ re $1 \mu \mathrm{Pa}$ at 1 meter was chosen to allow for variation in the model results and achieve $500 \mathrm{~m}$ zone of influence. The device transmitted a 1-second, $1-3 \mathrm{kHz}$ warble with a source level of $170 \mathrm{~dB}$ every 20 seconds during a 6.2-hour experimental period during daylight hours. After receiving the acoustic instrumentation system from the vendor and prior to deploying it for the filed study, the Project Team bench tested the sound source to ensure it was working properly.

\section{Methods}

Research activities were originally planned to commence in January 2010; however, a combination of process and permitting delays postponed the start date of active research to the next gray whale migration season in January 2011. On January 8, 2011, the acoustic device was moored on the seafloor approximately $5 \mathrm{~km}$ west of Yaquina Head, Oregon, in the path of migrating gray whales. To ensure that no animals were exposed to the full source level without prior opportunity to move away from it, the device was programmed such that at the beginning of each experimental period, it began transmitting at a lower source level $(120 \mathrm{~dB})$ and gradually ramped up to $170 \mathrm{~dB}$ over a 10 -minute period.

In mid-February 2011, the device had to be retrieved after a failure in the waterproof housing structure caused extensive damage to the instrumentation system. The hardware and sound source were returned to the manufacturer and the electronics enclosure was redesigned to prevent such incidents. However the Project Team did not receive the redesigned equipment until October 2011. As a result, the research was postponed until the next migration season (in 2012).

In January 2012, the acoustic deterrent prototype was re-deployed off the coast of Yaquina Head during the southbound whale migration. Observations were conducted on 51 days between January 1 and April 15, 2012. A total of 143 individual whale locations were collected for a total of 243 whales, as well as 57 tracklines for a total of 142 whales. However, the loss of surface buoys due to extreme weather and damage from commercial crabbing gear prevented the recovery of the deterrent mid-season to change batteries. Further, the batteries used in the instrumentation system did not perform as expected, resulting in loss of power that prevented the signal from transmitting during the planned experimental periods. As a result, only the experimental periods for the first 35 days of the study provided usable data. 


\section{Results \& Next Steps}

The study hypothesized that the acoustic deterrence signal would keep gray whales $500 \mathrm{~m}$ away from the device, so data reduction focused on a statistical analysis of whale presence at $500-\mathrm{m}$ and $2-\mathrm{km}$ distances. The combination of bad weather and equipment problems, however, resulted in a smaller sample size than required to detect a difference in whale locations between experimental and control periods. Additionally, the hypothesized zone of influence $(500 \mathrm{~m})$ was so small that few whales traveled within that zone, even during control periods. Despite the smaller sample size, statistical analysis of the proportions of experimental locations in 500-meter rings did not show a significant difference between the expected 500-meter zone of influence and areas out to $3 \mathrm{~km}$. This analysis indicates that the source level (volume) of the deterrence device was insufficient to prevent whales from entering the 500-meter zone. Due to inadequate sample size, however, the results of the 2012 study were inconclusive. OSUMMI researchers prepared a scientific report, Testing the effectiveness of an acoustic deterrent for gray whales along the Oregon coast, documenting the study and outcomes (Lagerquist, et. Al 2012).

\section{A. Refined Methods \& Equipment}

Based on the recommendations of marine mammal and acoustic experts, it was determined that the source level should be increased to $179 \mathrm{~dB}$. Further, researchers concluded that the zone of influence should be increased to $3 \mathrm{~km}$ to ensure the collection of adequate sample sizes. In light of these conclusions, the Project Team determined that another season of field testing was warranted to test the effectiveness of the deterrent device. Utilizing internal research funds, the Project Team completed modifications to the acoustic device and secured new permits for the 2013 research season.

In addition, the Project Team leveraged the experience form the previous study activities to improve and optimize key aspects of the project.

Project Management: The Project Team developed and implemented strong project management plan for the 2013 study season. In particular, the Project Team held weekly conference calls early in the season to review progress for the prior week and plans for the upcoming week. Team members also received a weekly summary of activities from the week prior to focus the group discussions. This information included observations for the prior week, as well as cumulative results, a weather outlook for the coming week, and an indication of any problems encountered.

$>$ Permitting: Recognizing that close coordination with regulatory agencies is a key factor in the permitting process, the Project Team initiated and maintained ongoing communication with the agencies to prevent permitting delays for the 2013 research season. The availability of potential effects analysis prepared for the original research permits also facilitated agency decisionmaking for the 2013 research permits. On December 21, 2012, NMFS issued Permit No. 1548301 to OSUMMI to authorize use of the increased source level (which amended and replaced the previous NMFS research permit). On December 10, 2012 the U.S. Coast Guard issued a letter of approval authorizing deployment of the surface float and navigational markers through June 
2013. A revised use permit from the Oregon Department of State Lands was also obtained, and the original Army Corps permit was extended until April 30, 2013.

Hypothesis: Based on the results of and insight gained from the 2012 research, the Project Team revised the study hypothesis to increase the deterrence distance from 500 to 3,000-meters. To accomplish this goal, OSUMMI consulted with other marine mammal and ocean acoustic experts and determined that increasing the source level from 170 to $179 \mathrm{~dB}$ re $1 \mu \mathrm{Pa}$ at 1 meter should keep $50 \%$ of the migrating whales outside of the 3-kilometer zone of influence. The signal characteristic remained the same at 1 -second $1-3 \mathrm{kHz}$ warble and was repeated every 20 seconds during a 5.2 hour experimental period during daylight hours. The device was turned off during control periods and for the remaining hours of the day.

Methods: The Project Team performed a sample size analysis using the simplified hypothesis to reveal the required number of sample locations. To ensure that researchers can obtain the required sample size from the 2013 observation season, the Project Team refined the methodology by prioritizing scan sampling and shortening focal follow tracking to concentrate on the area near the deterrent (as opposed to more time-consuming longer distance focal follows).

$>$ Equipment: In addition to increasing the source level, modifications were made to increase the power of the acoustic transducer to accomplish the new $3 \mathrm{~km}$ zone of influence. Connections between the surface buoy and the transducer were reinforced to ensure the instrument and its surface buoy will withstand extreme weather conditions and interactions with crabbing gear. Additionally, device has been redesigned to include a battery pack that can power the instrumentation for the entire season without the need for recharging.

The Project Team is quite confident that - with these changes - the researchers will be able to determine whether the deterrent is effective at deflecting gray whales.

\section{Comparison of Actual Accomplishments with Goals \& Objectives}

As discussed previously, process delays, equipment failure, and inclement weather resulted in discrepancies between the planned and actual timing of project activities. In particular, permitting delays postponed the start of the active research was postponed until January 2011. Further, the 2011 field study was cut short when the device mooring failed during a severe storm, and equipment failures experienced during the 2012 field study resulted in an insufficient sample size. Because the southbound migration period only occurs once a year, the field research activities are particularly susceptible to even small delays in timing. As a result, each time a delay was encountered the field observations had to be postponed until the following season.

Despite these discrepancies, however, the actual accomplishments align well with the original objective of evaluating the effectiveness of an acoustic deterrent mechanism in deflecting migratory gray whales. By testing and refining the acoustic deterrence methodologies and equipment, this project has informed both the technical and economic feasibility of this type of system and its potential efficacy as mitigation measure for MHK facilities. In fact, it is largely because of the challenges faced in this project that the 
Project Team optimized the methods and equipment for acoustic deterrence systems. The implementation of this project fostered collaboration among the Project Team and marine mammal experts, as well as among academia and industry.

A successful deterrent device may serve as a valuable mitigation tool to protect gray whales in the event that MHK energy facilities pose a collision or entanglement risk. It may also be applicable to endangered baleen whales in the Outer Continental Shelf, such as blue, fin, and humpbacks, as ocean energy development moves offshore into their habitat. Such a device may also have value as mitigation for other potentially harmful situations, such as oil spills or when whales stray out of their natural habitat and are in danger of stranding or starvation (Lagerquist et. al 2012). By informing the development of mitigation measures that can facilitate MHK siting, this project helps accelerate development of clean, affordable energy generation that is economically viable and environmentally responsible.

\section{Products}

The primary product developed under the award is the Acoustic Deterrence Device Electronics Package, which is described in details in the Draft and Final Scientific Reports prepared under the DOE award contract. Publications and outreach materials developed as part of the project are listed below and included in Appendix A; all of these materials have been provided previously to DOE. Final and interim research results have been made available to the public through publication in peer-reviewed scientific journals, preparation of contract reports, as well as presentations at scientific conferences and industry forums.

\section{Publications}

- Testing the effectiveness of an acoustic deterrent for gray whales along the Oregon coast. (Draft Scientific Report, 2012)

- Documenting behavioral response to an acoustic signal which has been designed to encourage whales to slightly adjust their migration route. (Final Scientific Report, 2013, In press)

\section{Presentations/Outreach Materials}

- Town Hall Meeting Invitation

- Gray Whale Study Overview

- Presentation at OWET Conference

\section{References}

Boehlert, G.W., G.R. McMurray and C.E. Tortorici, Eds. 2008. Ecological effects of wave energy in the Pacific Northwest. U.S. Dept. Commerce, NOAA Tech. Memo. NMFS-F/SPO-92.

Dolman, S. and Simmonds, M. 2010. Towards best environmental practice for cetacean conservation in developing Scotland's marine renewable energy. Marine Policy, 34: 1021-1027. 
Gill, A. B. 2005. Offshore renewable energy: ecological implications of generating electricity in the coastal zone. Journal of Applied Ecology, 42: 605-615.

Lagerquist, B., M. Winsor and B.R. Mate. 2012. Testing the effectiveness of an acoustic deterrent for gray whales along the Oregon coast. Draft Scientific Report Submitted to the U.S. Department of Energy. 31 pp. Available from Oregon State University Marine Mammal Institute, 2030 SE Marine Science Drive, Newport, OR 97365.

Ortega-Ortiz, J.G. and B.R. Mate. 2008. Distribution and movement patterns of gray whales migrating by Oregon: Shore-based observations off Yaquina Head, Oregon, December 2007-May 2008. Report submitted to the Oregon Wave Energy Trust. 34 pp. Available at: http://www.oregonwave.org/marine-mammal-study/

Wilson, B. R., Batty, S., Daunt, F. and Carter, C. 2007. Collision risks between marine renewable energy devices and mammals, fish and diving birds. Report to the Scottish Executive. Scottish Association for Marine Science, Oban, Scotland, PA37 1QA. 
DE-EE0002660 - FINAL TECHNICAL REPORT ACTIVE ACOUSTIC DETERRENCE OF MIGRATORY WHALES

\section{Appendix A: Outreach Materials}




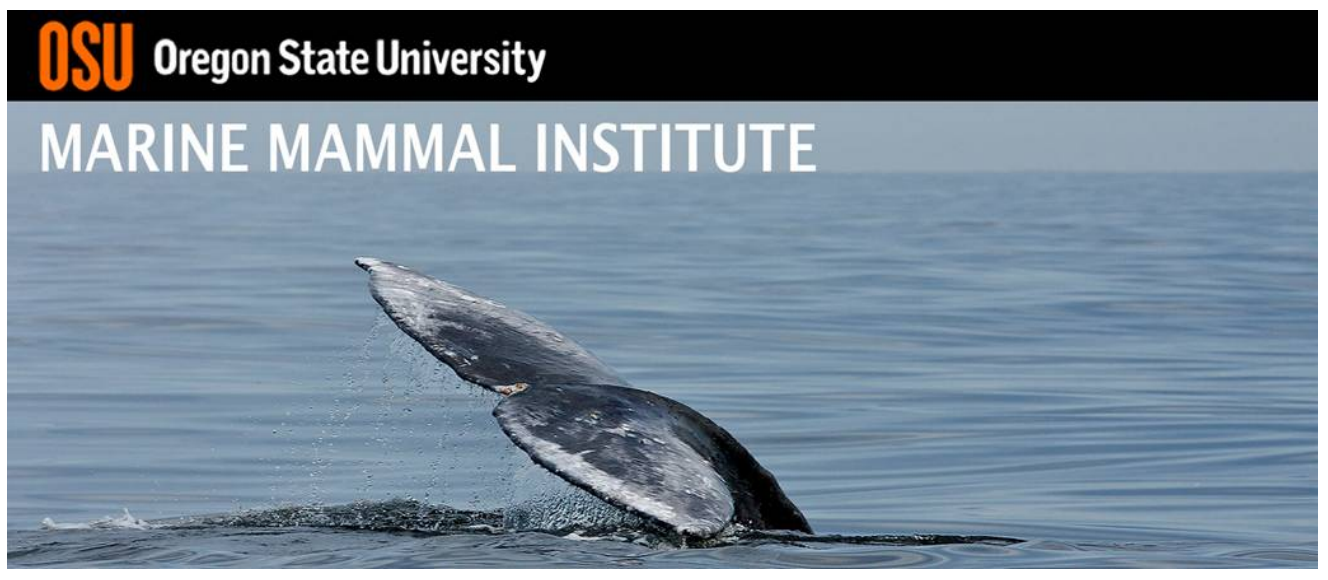

Please join the OSU Marine Mammal Institute for a Town Hall Meeting about the Development of a Gray Whale Protection Device

\author{
Wednesday, May 12 th 7:00-8:30 pm \\ Hennings Auditorium, HMSC Visitor Center
}

There is a great interest in harnessing wave energy off the Oregon Coast. An important issue in ocean renewable energy development is the risk of gray whales becoming entangled in or colliding with ocean renewable energy device mooring systems. The Marine Mammal Institute at OSU will test the effectiveness of an acoustic device to protect whales if these ocean renewable energy device mooring systems become a hazard for them. If successful, this device could also be used to keep whales out of harm's way from other calamities, like oil spills.

The purpose of this meeting is to inform local residents and interested parties about the study and to provide an opportunity to address any questions or concerns. An overview of the study will be presented, along with detailed information sheets about the project. After the presentation, Dr. Bruce Mate, director of the Marine Mammal Institute at OSU, will answer questions about the study.

\title{
For more Information:
}

Marine Mammal Institute

Hatfield Marine Science Center

2030 SE Marine Science Drive

Newport, Oregon 97365

Phone: 541-867-0202

E-mail: MMI Web@oregonstate.edu 


\section{Development of a Gray Whalle Protection Device}

About 18,000 gray whales migrate between Baja, Mexico and the Bering Sea every year. While gray whales navigate the coast regularly, there is concern that deployments of ocean renewable energy devices could pose a risk of entanglement or physical collisions. Although it has not been determined that ocean renewable energy devices would result in harm to whales, a panel of marine mammal experts has concluded that, if problems are encountered, acoustic warning systems could provide an effective mitigation strategy.

WHO: OSU's Marine Mammal Institute, directed by Dr. Bruce Mate, strives to advance conservation and the understanding of marine mammals by studying their ecology, distribution, habitats, and population abundance, as well as ocean health issues and the impact of anthropogenic activities on marine mammals. This study is sponsored by the U.S. Department of Energy.

WHAT: A study to test the effectiveness of an acoustic deterrence system in deflecting migratory gray whales around ocean renewable energy devices. The project will include the following elements:

PERMITTING

September 2010

The initial phase involves securing the necessary permits for the acoustic deterrence system.

\section{DEPLOYMENT}

December 2010

After the acoustic deterrence system is deployed, the research team will map its acoustic level at varying distances from the source.

\section{OBSERVATION}

January 2011 - mid-April 2011

Once deployed, the research team will conduct shore-based observations of migrating gray whales in the immediate vicinity during operation of the deterrent device to determine how far whales stay away from the device (the expectation is $500 \mathrm{~m}$, less than $1 / 3$ mile).

\section{ANALYSIS/SUMMARY}

September 2011

The project will conclude with data analysis, a written report, a scientific publication, and culminate with dissemination of the results at scientific and stakeholder meetings.

WHEN: The active field study will be conducted from January to mid-April, 2011, which will not include the main north-bound mother-calf migration.

WHERE: Yaquina Head, located on the central Oregon coast, and the waters directly offshore, will be used as the study site for the deployment and testing of the acoustic deterrence system.

WHY: Gray whales do not have a sophisticated sonar system. By emitting low frequency sounds, they may identify large features for navigation, but not smaller features like the 4-6" diameter mooring cables. If problems develop with whales inadvertently running into these cables, this device may offer a means of keeping them at a distance.

HOW: The proposed system would function similarly to small acoustic deterrent devices, also known as pingers, used on fishing nets, which have proved effective in reducing bycatch of marine mammals in gill net fisheries. 
DE-EE0002660 - FINAL TECHNICAL REPORT ACTIVE ACOUSTIC DETERRENCE OF MIGRATORY WHALES

\section{Appendix B: Project Permits}


[Federal Register: November 8, 2010 (Volume 75, Number 215)] [Notices] [Page 68605] From the Federal Register Online via GPO Access [wais.access.gpo.gov] [DOCID:fr08no10-42]

[[Page 68605]]

DEPARTMENT OF COMMERCE

National Oceanic and Atmospheric Administration

[File No. 15483]

RIN 0648-XX23

Marine Mammals

AGENCY: National Marine Fisheries Service (NMFS), National Oceanic and Atmospheric Administration (NOAA), Commerce.

ACTION: Notice; issuance of permit.

SUMMARY: Notice is hereby given that Bruce Mate, $\mathrm{PhD}$, Oregon State University, Hatfield Marine Science Center, Newport, OR has been issued a permit to conduct research on marine mammals.

ADDRESSES: The permit and related documents are available for review upon written request or by appointment in the following office(s):

Permits, Conservation and Education Division, Office of Protected Resources, NMFS, 1315 East-West Highway, Room 13705, Silver Spring, MD 20910; phone (301) 713-2289; fax (301) 713-0376; and Northwest Region, NMFS, 7600 Sand Point Way NE, BIN C15700, Bldg. 1, Seattle, WA 98115-0700; phone (206) 526-6150; fax (206) 526-6426.

FOR FURTHER INFORMATION CONTACT: Tammy Adams or Kristy Beard, (301) 713-2289.

SUPPLEMENTARY INFORMATION: On July 13, 2010, notice was published in the 
Federal Register (75 FR 39915) that a request for a permit to conduct research on gray whales (Eschrictius robustus) had been submitted by the above-named applicant. The requested permit has been issued under the authority of the Marine Mammal Protection Act of 1972, as amended (16 U.S.C. 1361 et seq.), the regulations governing the taking and importing of marine mammals (50 CFR part 216), the Endangered Species Act of 1973, as amended (ESA; 16 U.S.C. 1531 et seq.), and the regulations governing the taking, importing, and exporting of endangered and threatened species (50 CFR parts 222-226).

The permit authorizes takes of marine mammals by level $B$ harassment during a study to evaluate the effectiveness of an underwater acoustic deterrent device at diverting gray whales migrating past the coast of central Oregon between January and mid-April away from the sound source. The permit also authorizes incidental level $B$ harassment of harbor porpoise (Phocoena phocoena), Southern Resident and West Coast Transient killer whales (Orcinus orca), harbor seals (Phoca vitulina), California sea lions (Zalophus californianus), Eastern Distinct Population Segment Steller sea lions (Eumetopias jubatus), and Northern elephant seals (Mirounga angustirostris). The permit is valid for five years from the date of issuance.

In compliance with the National Environmental Policy Act of 1969 (42 U.S.C. 4321 et seq.), an environmental assessment (EA) was prepared analyzing the effects of the permitted activities on the human environment. Based on the analyses in the EA, NMFS determined that issuance of the permit would not significantly impact the quality of the human environment and that preparation of an environmental impact statement was not required. That determination is documented in a Finding of No Significant Impact (FONSI), signed on October 29, 2010.

As required by the ESA, issuance of this permit was based on a finding that such permit: (1) Was applied for in good faith; (2) will not operate to the disadvantage of such endangered species; and ( 3 ) is consistent with the purposes and policies set forth in section 2 of the ESA.

Dated: November 2, 2010.

P. Michael Payne, Chief, Permits, Conservation and Education Division, Office of Protected Resources, National Marine Fisheries Service.

[FR Doc. 2010-28169 Filed 11-5-10; 8:45 am] BILLING CODE 3510-22-P 
To: Dr. Bruce R. Mate

Dept: CAS/Marine Mammal Institute

Subj: Animal Care and Use Proposal

Project Title: Development of an acoustic deterrent device for Eastern North Pacific gray whales.

Project Status: Your proposal for the use of animals has been reviewed and approved by the IACUC. ACUP Number: 4099

Approval Date: 11/17/10

Renewal Dates: 11/16/11, 11/16/12

(Renewal is required every year)

Expiration Date: 11/16/13

(New Animal Care and Use Form Submitted)

Principal Investigators are advised that the Animal Welfare Act (AWA) and the Public Health Service (PHS) policy requires that any significant changes to your protocol (i.e., changes in animal numbers, housing, procedures, substances administered, personnel, etc.) previously authorized by IACUC, must be approved by the IACUC via submission of an Amendment Form. Implementing significant changes without prior IACUC approval violates regulations for animal welfare.

Annual Renewal of your ACUP is required. A reminder will be sent to you to either close or renew this project by completing the Annual Renewal Form. It is imperative that the annual renewal is completed and submitted by the due date indicated.

Adverse Events: The IACUC requires investigators to submit an Adverse Event for any unexpected injuries to animals during the course of the project. An Adverse Event is any happening not consistent with routine expected outcomes that results in any unexpected animal welfare issues (death, disease, or distress) or human health risks (zoonotic or injuries).

If you have any questions, please contact the IACUC Administrator at IACUC@ oregonstate.edu or by phone at (541) 737-2762.

USDA Research Facility

Certificate \# 92-R-0005

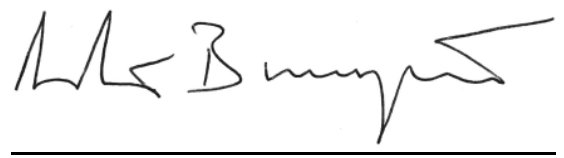

Dr. Andrew Buermeyer

IACUC Chair
Office of Laboratory Animal

Welfare (OLAW)

Assurance \# A3229-01

November 17, 2010

Date 


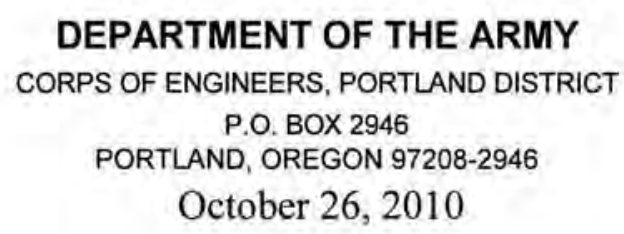

REPLYTO

ATTENTION OF:

Operations Division

Regulatory Branch

Corps No.: NWP-2010-385

Mr. Bruce Mate

Oregon State University

Marine Mammal Institute

2030 SE Marine Science Drive

Newport, OR 97365

Dear Mr. Mate:

The U.S. Army Corps of Engineers (Corps) received your request for Department of the Army authorization to conduct scientific research related to the behavior of migrating gray whales in the Pacific Ocean in approximately 50 meters of water, 2.5 nautical miles off of the coast near Newport, Lincoln County, Oregon. The device further would be located within $500 \mathrm{~m}$ of the following coordinates: latitude 44.676 North and longitude -124.140 West.

The Project consists of deploying a scientific measurement device, including one anchor, an acoustic emitter ("pinger"), a mooring line, and a surface buoy. The anchor is a concrete block that weighs approximately 1 ton and has a volume of approximately 0.43 cubic meters. The Project will be deployed between December 2010 and May 2011 in the Pacific Ocean just west of Yaquina Head near Newport, Oregon. Whales will be monitored for any behavioral response to the acoustic pinger.

The scientific instrument ("Project") that will be deployed at the project site (see Enclosure 1) consists of the following components;

1. Acoustic Source - The Acoustic Source is a battery-powered transmitter (approximately $40 \mathrm{~cm}$ long by 34 centimeters wide by 17 centimeters tall) that provides the electronic signal to the Acoustic Projector. The Acoustic Source is located at ocean bottom and is connected to the Anchor. The Acoustic Source is powered by an Optima 12V $1000 \mathrm{AHr}$ battery and both the transmitter and the battery will be housed in a waterproof box.

2. Acoustic Projector - The Acoustic Projector is connected to the Acoustic Source and will be located approximately 20 -meters below the surface of the ocean. The Acoustic Projector is approximately $20 \mathrm{~cm}$ in diameter $6 \mathrm{~cm}$ thick and weighs approximately $5 \mathrm{~kg}$. The Acoustic Projector is connected to the Acoustic Source by an electrical cable, 
3. Surface Floats - The Acoustic Source will be attached to one (1) or two (2) Surface Floats). The Surface Floats are standard 0.56-meter diameter orange or yellow floats in accordance with USCG standards.

4. Radar Reflector - A radar reflector in accordance with USCG Private Aids to Navigation (PATON) will be attached to the surface floats on a 3-meter mast.

5. Navigation Light - A navigation light will also be attached to the Surface Floats as required by the USCG. The light will be yellow and will flash at a rate to be prescribed by the USCG upon issuance of a letter of authorization (Figure 6).

6. Anchor - The Anchor is a concrete block that weighs approximately 1 metric ton. The dimensions of the anchor are approximately 120 centimeters long by 60 centimeters wide by 60 centimeters high. The anchor will be lowered into position from a vessel mounted crane.

7. Mooring Line - The Surface Floats are connected to the Anchor with a combination of synthetic rope and anchor chain. A scope of approximately 2:1 will be used for the mooring line (e.g. - if the water depth is 50 -meters then the length of the mooring line will be 100 -meters).

This letter verifies that your project is authorized under the terms and limitations of Nationwide Permits (NWP) Nos. 1 (Aids to Navigation) and 5 (Scientific Measurement Devices). Your activities must be conducted in accordance with the conditions found in the Portland District NWP Regional Conditions (Enclosure 2) and the NWP General Conditions (Enclosure 3). You must also comply with the Oregon Department of Land Conservation and Development (DLCD) Coastal Zone Management Concurrence Conditions (Enclosure 4) and the project specific condition below. Failure to comply with any of the listed conditions could result in the Corps initiating an enforcement action.

a) Permittee shall notify the Regulatory Branch with the start date the activities authorized in waters of the United States are scheduled to begin. Notification shall be sent by email to cenwp.notify@usace.army.mil or mailed to the following address:

\author{
U.S. Army Corps of Engineers \\ CENWP-OD-GC \\ Permit Compliance, Lincoln County \\ Post Office Box 2946 \\ Portland, Oregon 97208-2946
}

The subject line of the message shall contain the name of the county in which the project is located followed by the Corps of Engineers permit number. 
We direct your attention to NWP General Condition 25 (Enclosure 3) that requires the transfer of this permit if the property is sold, and NWP General Condition 26 that requires you to submit a signed certificate when the work is completed. A "Compliance Certification" is provided (Enclosure 5).

This authorization does not obviate the need to obtain other permits where required. Such permits also must be obtained before work begins.

This verification is valid until the NWP is modified, reissued, or revoked. All of the existing NWPs are scheduled to be modified, reissued, or revoked prior to March 18, 2012. It is incumbent upon you to remain informed of changes to the NWPs. We will issue a Public Notice when the NWPs are reissued. Furthermore, if you commence or under contract to commence this activity before the date the relevant NWP expires, is modified or revoked, you will have 12 months from the date of the modification, or revocation of the NWP to complete the activity under the present terms and conditions of this NWP.

We would like to hear about your experience working with the Portland District, Regulatory Branch. Please complete a customer service survey form at the following address: http://per2.nwp.usace.army.mil/survey.html.

If you have any questions regarding this NWP verification, please contact Mr. Tom Taylor at the letterhead address, by telephone at (503) 808-4386, or by e-mail at thomas.j.taylor@usace.army.mil.

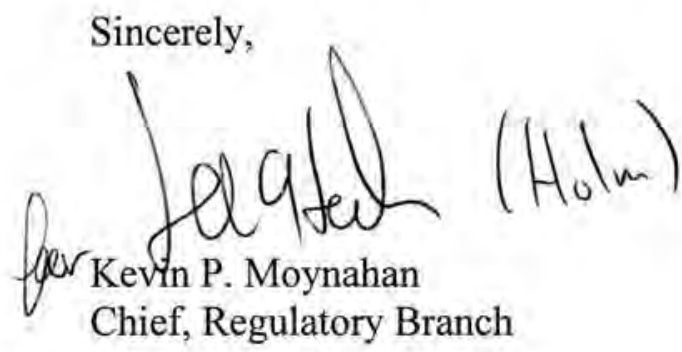

Enclosures

Copy Furnished via email w/o enclosures:

Oregon Department of Environmental Quality (Saxon)

Oregon Department of Land Conservation and Development (Hickner) 


\section{COMPLIANCE CERTIFICATION}

U.S. Army Corps of Engineers

CENWP-OD-GC

Post Office Box 2946

Portland, Oregon 97208-2946

1. Permittee Name: Mr. Bruce Mate, Oregon State University, Marine Mammal Institute, 2030 SE Marine Science Drive, Newport, OR 97365

2. County: Lincoln

2. Corps Permit No: NWP-2010-385

3. Corps Contact: Tom Taylor

4. Type of Activity: 1 (Aids to Navigation) and 5 (Scientific Measurement Devices)

\section{Please sign and return form to the address above:}

I hereby certify that the work authorized the above referenced permit has been completed in accordance with the terms and conditions of said permit and that required mitigation is completed in accordance with the permit conditions, except as described below.

Signature of Permittee Date


四

US Army Corps of Engineers

Portland District
Oregon Department Land Conservation And Development (DLCD)

Coastal Zone (CZM) Management Concurrence

$\underline{\text { Standard CZM Conditions - Appendix A }}$

All projects permitted, licensed, or funded by the federal government are subject to review for consistency with the Oregon Coastal Management Program (OCMP). Conditions may be placed on federal permits, licenses, or funding to ensure consistency with the OCMP. The 10 Standard CZM conditions given below are required as part of that consistency concurrence for Nationwide Permits issued in Oregon's Coastal Zone.

Appendix B provides an explanation of why the conditions are necessary to ensure consistency with specific enforceable policies of the management program, and an identification of the specific enforceable policies relevant to each condition.

An applicant may choose to not follow one or more of the OCMP conditions. In that instance, an agreement between the OCMP and the applicant must be reached on what conditions will be attached to the federal permit, license or action.

Failure to come to an agreement shall trigger an objection to the federal action by the OCMP. In that instance, the permittee may appeal the state's objection to the Secretary of Commerce, pursuant to 15 CFR 930; subpart $\mathrm{H}$, within 30 days of receipt of the letter informing the applicant of the OCMP's objection. (Ref. 15 CFR 930.63(e)) In order to grant an override request, the Secretary must find that the activity is consistent with the objectives or purposes of the Coastal Zone Management Act, or is necessary in the interest of national security. A copy of the request and supporting information must be sent to the OCMP and the federal funding, permitting or licensing agency. The Secretary may collect fees from the permittee for administering and processing the request. (Ref 15 CFR 930.63,11-07 Edition)

Appendices A \& B addresses the requirements of 15 CFR 930.4(a) (1).

\section{CZ Condition 1. Consistency with Local Comprehensive Plans.}

(1) Authorization for projects in Oregon's coastal zone under any nationwide permit is valid only if the proposed project is consistent with or not subject to the applicable local comprehensive plan and implementing land use regulations, or to the statewide land use planning goals where applicable. Permits or other authorizations must be obtained, when required, from the applicable local government before work is initiated under any nationwide permit. Verification of the local jurisdiction's decision must be given to the Corps of Engineers in the form of a completed block seven (7) of the Joint Permit Application. All appeals of the local jurisdiction's decision(s) must be resolved before any regulated work may begin.

(2) All conditions placed on an authorization or permit by the local government are incorporated by reference into the conditions for consistency concurrence by the Oregon Coastal Management Program.

\section{CZ Condition 2. Consistency with Removal-Spill} Law.

(1) Authorization for projects in Oregon's coastal zone under any nationwide permit is valid only if the proposed project is consistent with or not subject to the state statutes for state lands and removal-fill in waters of the state. Permits or other authorizations must be obtained when required from the Oregon Department of State Lands (DSL) before any regulated work may begin.

(2) For projects found not subject to the Removal/Fill Law by DSL, any changes in project design or implementation which may reasonably be expected to require application of the Removal/Fill Law shall be submitted to DSL for review.

(3) All conditions placed on a Removal-Fill permit by the Oregon Department of State Lands are incorporated by reference into the conditions for consistency concurrence by the Oregon Coastal Management Program. 
CZ Condition 2a. Leases of State Lands.

(1) Authorization for projects in Oregon's coastal zone under any nationwide permit is valid only if the proposed project has obtained any required lease or other license required for the use of state lands or waters. Permits or other authorizations must be obtained when required from the Oregon Department of State Lands (DSL) before any regulated work may begin.

(2) All conditions placed on a lease, license, or authorization by the Oregon Department of State Lands are incorporated by reference into the conditions for consistency concurrence by the Oregon Coastal Management Program.

\section{CZ Condition 3. Department of Environmental Quality.}

(1) Authorization for a project in Oregon's coastal zone under any nationwide permit is valid only if the proposed project has been certified or does not require certification by the Oregon Department of Environmental Quality (DEQ) through its 401 Water Quality Certification process.

(2) All conditions placed on a DA license, permit, or authorization by the Oregon Department of Environmental Quality are incorporated by reference into the conditions for consistency concurrence by the Oregon Coastal Management Program.

\section{CZ Condition 4. In-Water Work.}

(1) All in-water work, including temporary fills or structures, shall occur within the ODFW recommended period for in-water work for the affected water body. Exceptions to the recommended time periods require specific approval from the Corps, and:

(i) The Corps shall coordinate exceptions to work windows with ODFW and NMFS (NOAA Fisheries). Decisions to not apply ODFW or NMFS work windows shall be accompanied by written approval from ODFW;

(ii) On tribal lands, the Corps shall coordinate exceptions with the EPA.

(2) No work shall be authorized within or directly impacting areas identified by the Oregon Department of Fish and Wildlife (ODFW) as used by or susceptible for use by spawning fish, unless approved by ODFW. This restriction shall apply year-round, and is not limited by spawning season or by the presence or absence of fish at any given time.

CZ Condition 5. Fish and Aquatic Life Passage. (1) Where applicable, all authorized projects shall be in conformance with ODFW standards for fish passage http://www.dfw.state.or.us/fish/passage/ decisions to abrogate ODFW fish passage standards shall be accompanied by written approval from ODFW.

(2) No work shall be authorized that does not provide for adequate passage of "aquatic life." Aquatic life shall be interpreted to include amphibians, reptiles, and mammals whose natural habitat includes waters of this state and which are generally present in or around, or pass through the project site.

(3) This condition is effective only where ODFW regulations apply.

\section{CZ Condition 6. Heavy Equipment Use}

(1) Heavy equipment shall be operated from the bank, and not placed in a stream unless specifically authorized. In-stream work may be authorized by the Corps of Engineers if necessary in the interest of safety or due to site conditions prohibiting work from the bank.

(2) Heavy equipment in wetlands or on soft soils must be placed on mats or other similar devices to minimize damage to natural resources.

(i) If the period of use of heavy equipment on the wetland area will exceed 14 (fourteen) calendar days from start to finish, the applicant/permittee shall notify the Corps prior to starting the work. The Corps shall assess if the longer work period is necessary, and what additional protective measures may be required to minimize or mitigate the impacts.

(ii) All mats or other protective measures shall be removed at the end of each workday unless the Corps determines that to do so would cause greater harm to the resource. 
(3) Irrespective of measures taken to limit unintended impacts from heavy equipment, any damage done to vegetation, land, or waterways within or impacting waters of the state beyond the scope of the permit shall be mitigated.

(4) This condition is effective only in situations where the Removal-Fill Law applies.

\section{CZ Condition 7. Collateral Damage}

(1) Permittees shall be required to repair, restore, or mitigate for any and all impacts within or impacting waters of the state which occur in the course of the work, including those beyond the scope of the permitted work, whether intentional or unintentional, including those impacts due to accident, misinterpretation, or misunderstanding.

(2) This condition is effective only in situations where the Removal-Fill Law applies.

\section{CZ Condition 8. Multiple Permits}

(1) For each NWP-authorized activity, the acreage of impact for a permitted activity shall not exceed the limit for that specific permit. When there are two or more nationwide permits combined for a single project site, the impact for each activity must be limited to that specifically permitted under each applicable NWP. For example, when combining two NWPs at a single site, if one nationwide permit authorizes $1 / 4$ acre of impact for a house, and another $1 / 4$ acre of impact

for a road, the total impact due to the house may not exceed $1 / 4$ acre.

(2) This condition is effective only in situations where the Removal-Fill Law applies.

\section{CZ Condition 9. Aquaculture}

(1) For projects involving commercial aquaculture or mariculture cultivation of oysters, clams, and mussels, authorization for projects in Oregon's coastal zone under a nationwide permit is valid only if the applicant has obtained authorization, as required, from the Oregon Department of Agriculture (ODA) for use of state submerged and submersible lands for aquaculture purposes.

(2) All conditions placed on an aquaculture or mariculture operation by the ODA are incorporated by reference into the conditions for consistency concurrence by the Oregon Coastal Management Program.
(3) This condition is effective only in situations under the jurisdiction of the ODA.

\section{$\underline{\text { CZM Concurrence - Appendix B }}$}

\section{$\underline{\text { Standard CZM Conditions - Basis in Law }}$}

This appendix provides an explanation of why the conditions given in Appendix A are necessary to ensure consistency with enforceable policies of the Oregon Coastal Management Program, and references the specific enforceable policies relevant to each condition. This Appendix addresses the requirements of 15 CFR 930.4(a) (1).

\section{CZ Condition 1. Consistency with Local Comprehensive Plans.}

OAR 660-031-0030 requires denial of a state permit when a proposed activity is not in compliance with a Statewide Planning Goal or compatible with an Acknowledged Comprehensive Plan. Further support for this condition is found in ORS 197.1 80(1) (a \& b), which requires compliance with goals and acknowledged plans.

Paragraph two is considered a logical extension of the requirements of -0030 and 197.180 . Any condition required for local approval must also be an enforceable provision of the coastal program (through the Goals and acknowledgement) to be included in the federal permit to ensure consistency.

\section{CZ Condition 2. Consistency with Removal-Fill Law.}

The OCMP states that the general criteria for assessing consistency are whether the activity or project conforms to the mandatory policies set forth in applicable state statutes and rules. (Green Book, p 51) Those statutes are found in Table 3, page 23, of the Green Book. As referenced in the Green Book, ORS 541 (later renumbered ORS 196 in 1987) is the Removal-Fill Law. DSL is responsible for administering this law, and the decision to issue a permit or find no jurisdiction constitutes an affirmative determination of consistency with the Removal-Fill Law. (Green Book, P 17) 
Paragraph two is considered a logical extension of the requirements of ORS 196. Any condition required for state approval must also be an enforceable provision of the coastal program (through the Goals and plan acknowledgement) to be included in the federal permit for consistency.

\section{CZ Condition 2a. Leases of State Lands.} OAR 141-082-0060 gives DSL the authority to place terms on a lease of state lands as it sees fit. This rule is based upon ORS 274 .

Paragraph two is considered a logical extension of the requirements of -0060 and ORS 274 . Any condition required for state approval must also be an enforceable provision of the coastal program to be included in the federal permit for consistency.

\section{CZ Condition 3. Department of Environmental Quality.}

The OCMP states that the general criteria for assessing consistency are whether the activity or project conforms to the mandatory policies set forth in applicable state statutes and rules. (Green Book, p 51) Those statutes are found in Table 3, page 23, of the Green Book. ORS 454,459, 467, and 468 are referenced as DEQ authorities under the OCMP.

* Note. To be valid any condition asserted under consistency determination must be based on an authority included in the OCMP. Any other authority may be valid under the requirements of Section 401 of the Clean Water Act, but would not be valid for federal coastal zone consistency. ORS 454,459,467 and 468 are referenced as DEQ authorities under the OCMP. Coastal Zone condition 3 is independent of any other conditions DEQ might place on a 401 certifications which are based on authorities other than $454,459,467$, and 468.

\section{CZ Condition 4. In-Water Work.}

(1) The Fish and Wildlife Commission is responsible for the protection and management of fish and wildlife in the state. (ORS 496.012) Any federal action should be fully consistent with ODFW policies promulgated under ODFW authorities (ORS 496,498, 501, and 506), irrespective of ORS 196 (Removal-Fill Law) or other authorities.
ODFW promulgated the Oregon Guidelines for Timing of In-Water Work to Protect Fish and Wildlife Resources under ORS 496.012 and 496.138. OAR 141-085-0029(9) (c) requires consultation by DSL with ODFW if in-water work is requested outside the dates set by ODFW in the Guidelines. The Corps is given leave to abrogate these rules, but a clear record of their decision is appropriate.

(2) This condition is based upon the plenary authority of ORS 496.012, is consistent with SLOPES, but goes a little further in exerting ODFW authority.

\section{CZ Condition 5. Fish and Aquatic Life Passage.} The Fish and Wildlife Commission is responsible for the protection and management of fish and wildlife in the state (ORS 496.012). This is taken to include the management and protection of habitat, though 496.012 does not use 'habitat.' Any federal action should be $1 \mathrm{y}$ consistent with ODFW policies promulgated under OCMP-incorporated ODFW authorities (ORS 496,498, 501, and 506), regardless of ORS 196 (Removal-Fill Law) or other authorities. (Green Book, p 23)

ORS 509.585 sets out requirements for fish passage at artificial obstructions. ORS 509 was incorporated in the OCMP as a routine program change on March 20, 2002 in a letter to Nan Evans from John King.

"Waters of this state" shall be interpreted consistent with its meaning for ORS 496.012. See also definition given in OAR 141-085.

Relevant definitions: 141-085-0010 (5) "Aquatic Life and Habitats" means the aquatic environment including fish, wildlife and plant species dependent upon environments created and supported by the waters of this state. Aquatic life includes communities and species populations that are adapted to aquatic habitats for at least a portion of their life.

(225) "Waters of this State" means natural waterways including all tidal and non-tidal bays, intermittent and perennial streams (i.e., streams), lakes, wetlands and other bodies of water in this state, navigable and 
non-navigable, including that portion of the Pacific Ocean, which is in the boundaries of this state. "Waters of this state" does not include the ocean shore, as defined in ORS 390.605 .

496.004 (19) "Wildlife" means fish, shellfish, wild birds, amphibians and reptiles, and

feral swine as defined by State Department of Agriculture rule, and other wild mammals.

\section{CZ Condition 6. Heavy Equipment Use}

The basis for this condition is found at OAR 141$085-0029.7, .8$, and .9c \& d, and relates to the minimization of impacts generally for any activity.

\section{CZ Condition 7. Collateral Damage}

This condition is based upon OAR 141-0850029.9.c, minimization of impacts, and 141-0850079 , enforcement. This condition would extend a specialized provision to the NWP program based upon general provisions of the OAR. There are currently provisions in state law requiring this type of restoration, but nothing explicit. This would clarify an existing situation, making enforcement easier and bringing to bear the Corps' enforcement authority.

\section{CZ Condition 8. Multiple Permits}

OAR 141-089-0100(6) prohibits the use of more than one state general permit on a project. This condition brings Corps practice more in line with state enforceable policy. DSL approval is required for the modification of this condition.

\section{CZ Condition 9. Aquaculture}

ORS 622.220 gives ODA authority over shellfish aquaculture. ORS 622 is incorporated into the OCMP.

\section{CZM Concurrence: Appendix C}

Guidance for Determination of Denial of Advance Concurrence

Advance concurrence is not extended to the following two classes of permits:

- Any permit where the project is within or directly impacts the Territorial Sea (waters and seabed extending three (3) nautical miles seaward from the coastline, in conformance with federal law), excepting projects permitted under NWP 1 or NWP 5.

- Any project utilizing NWP 29 or NWP 39 requiring a local plan amendment, text amendment, zoning change, goal exception, discretionary decision, or action by a city or county council or commission.

The District Engineer shall be responsible for determining when proposed projects meet one or both of these circumstances. In these instances, the DLCD will undertake an individual review of the project to ensure proper adherence to the OCMP.

\section{Territorial Sea:}

Oregon's Territorial Sea extends from the shoreline seaward for a distance of three (3) nautical miles. Estuaries are not considered to be part of the Territorial Sea. Excepting projects permitted under NWP 1, Aids to Navigation, and NWP 5, Scientific Measurement Devices, any project which occurs on or under the Territorial Sea, or on or beneath the sea bottom, shall be reviewed on an individual basis by DLCD for consistency with OCMP. In addition, any project which results in new or increased activity or impacts on or under the Territorial Sea, or on or under the sea bottom, shall be reviewed on an individual basis by DLCD for consistency with OCMP.

Examples of activities falling under this exception include:

- Construction of an offshore structure or platform;

- Installation of wave or wind energy extraction devices and related infrastructure;

- Installation of a buried or exposed cable;

- A new or expanded port facility which increases ship traffic in the Territorial Sea; 
- A new or relocated shipping channel in the Territorial Sea.

These examples are illustrative, not comprehensive. Any questions regarding application of this criterion should be directed to the Oregon Coastal

Management Program office.

\section{NWP 29 and 39}

Advance concurrence is withheld from any project utilizing NWP 29 or 39 and requiring a local plan amendment, text amendment, zoning change, goal exception, discretionary decision, or action by a city or county council or commission. Such projects may be identified by block seven (7) of the Joint Permit Application.

Examples of situations falling under this exception include:

- Permit applications where the city/county has checked the box "This project is not consistent with the comprehensive plan.. ." in block seven (7) of the JPA;

- The project would require an amendment to a comprehensive plan;

- The project would require a change in zoning;

- The project would require an exception to a Statewide Planning Goal.

These examples are illustrative, not comprehensive. Any questions regarding application of this criterion should be directed to the Oregon Coastal Management Program office. 
Salem, OR 97301-1279

(503) $986-5200$

FAX (503) 378-4844

September 30, 2010

www.oregonstatelands.us.

State Land Board

Theodore R. Kulongoski

JV410\45364-AA

OREGON STATE UNIVERSITY

Governor

MARINE MAMMAL INSTITUTE

Kate Brown

DR BRUCE MATE

2030 SE MARINE SCIENCE DRIVE

NEWPORT OR 97365

RE: State Short Term Access Agreement 45364-AA

Dear Dr. Mate:

Enclosed is the fully executed short term access agreement for the access to stateowned submerged and/or submersible lands in the Territorial Sea in Lincoln County, Oregon, to allow the placement of scientific measuring device to research migrating gray whales.

This short term access agreement will allow access to the area between September 30, 2010 through May 31, 2011.

If you have any questions, please call me at 503-986-5262.

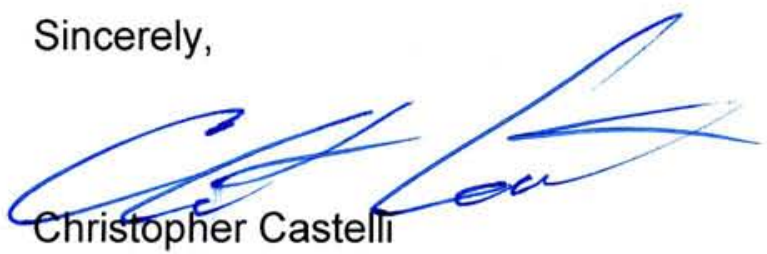

Land Manager

South Coast and Valley Region

Land Management Division

Enclosure 


\section{STATE OF OREGON \\ Department of State Lands \\ Short Term Access Agreement \\ Waterway \\ 45364-AA}

The STATE OF OREGON, Department of State Lands, GRANTOR, hereby grants to

NAME of GRANTEE:

Oregon State University

Marine Mammal Institute
ADDRESS:

2030 SE Marine Science Drive

Newport OR 97365

hereinafter called "GRANTEE", a Short Term Access Agreement upon the following described submerged and submersible land of the Pacific Ocean, hereinafter called "Lands in Use" described as follows:

State-owned submerged land in the Territorial Sea, adjacent to Lincoln County. A 500 meter radius around the point, Latitude $44.676^{\circ}$ North, Longitude $-124.140^{\circ}$ West, as shown on the attached Exhibit $A$.

Which are subject to the following terms and conditions:

1. The owner hereby grants to GRANTEE a Short Term Access Agreement upon the Lands in Use at any time from the date of this instrument until May 31, 2011, in order to place scientific measuring device to research migrating gray whales described herein, and further, the GRANTOR does hereby covenant that he is the lawful owner of a sufficient estate in the said Lands in Use to enable him to give the permission herein granted and that the said Lands in Use are free from any encumbrances which would interfere with the said permission.

2. This Short Term Access Agreement includes the right to ingress and egress on other lands of the GRANTOR described above, providing that the GRANTOR is given notification of such ingress and egress and such ingress and egress is approved by the GRANTOR, and provided such ingress and egress is necessary and not otherwise conveniently available to GRANTEE, and a Short Term Access Agreement for persons, pipelines, machinery and/or other equipment, over and across said Lands along such routes as may be necessary for the hereinabove stated purpose.

3. GRANTEE shall comply with all applicable local, state and federal laws and regulations affecting the Lands in Use and the use thereof, including local comprehensive land use planning and zoning ordinances, and correct at GRANTEE'S own expense any failure of compliance created through GRANTEE'S fault or by reason of GRANTEE'S use:

Dispose of all waste in a legal and proper manner and not allow debris, garbage or other refuse to accumulate within the Lands in Use; provided that, if GRANTEE allows 
debris, garbage or other refuse to accumulate within the Lands in Use, State shall have the right to remove the debris, garbage and other refuse, and collect the cost of such removal from GRANTEE;

Conduct all operations within the Lands in Use in a manner that conserves fish and wildlife habitat, protects water quality, and does not contribute to soil erosion or the infestation or spread of noxious weeds;

And, if applicable; maintain all buildings, docks, pilings, floats, gangways, similar structures, and other improvements located within the Lands in Use in a good state of repair; and

Not unreasonably interfere with the public's trust rights of commerce, navigation, fishing or recreation.

4. Submerged/Submersible Only In addition to any other applicable laws and regulations, GRANTEE shall comply with Oregon Department of Environmental Quality and Oregon State Marine Board requirements for sewage collection and waste water disposal for boats and floating structures.

5. GRANTEE shall not use, store, or dispose of, or allow the use, storage, or disposal within the Lands in Use of any materials that may pose a threat to human health or the environment, including without limitation, pollutants, hazardous solid waste, hazardous substances, pesticides, herbicides, or petroleum products (a "Hazardous Substance") except in strict compliance with applicable laws, regulations and manufacturer's instructions and shall take all necessary precautions to protect human health and the environment and to prevent discharge or release of any Hazardous Substance to the environment from the Lands in Use.

GRANTEE shall keep and maintain accurate and complete records of the amount of all such pollutants, hazardous solid waste, hazardous substances, pesticides, herbicides, or petroleum products (a "Hazardous Substance") stored or used on the Lands in Use, and shall immediately notify State of any release or threatened release of any such Hazardous Substance to the environment from the Lands in Use or otherwise attributable to operations or activities on the Lands in Use.

In the event any pollutants, hazardous solid waste, hazardous substances, pesticides, herbicides, or petroleum products (a "Hazardous Substance") is released, GRANTEE shall promptly and fully remediate such release in accordance with State and federal regulations and requirements. If GRANTEE fails to so remediate, State shall have the right to remove and remediate any release of a Hazardous Substance on the Lands in Use or attributable to operations or activities conducted or allowed by GRANTEE on the Lands in Use and to collect the cost of such removal or remediation from GRANTEE.

In addition to any duty to indemnify described elsewhere in this Short Term Access Agreement, GRANTEE shall indemnify State against any claim or costs arising from or related to a release of a pollutants, hazardous solid waste, hazardous substances, pesticides, herbicides, or petroleum products (a "Hazardous Substance") on or from the Lands in Use. 
6. All tools, equipment, and other property belonging to GRANTEE taken upon or placed upon the land by GRANTEE shall remain the property of GRANTEE and may be removed by GRANTEE at any time within a reasonable period after the expiration of this Short Term Access Agreement.

7. GRANTEE agrees to defend, indemnify and hold State harmless from and against all claims, demands, actions, suits, judgment, losses, damages, penalties, fines, costs, and expenses (including expert witness fees and costs and attorney's fees in an administrative proceeding, at trial, or on appeal) arising from or attributable, in whole or in part, to the access agreement or any operations conducted or allowed by GRANTEE on the Lands in Use. As used in this Section 7.0 only, "State" means the State of Oregon and its boards, commissions, agencies, officers, employees, contractors, and agent.

This Short Term Access Agreement may be cancelled by GRANTOR after thirty (30) days written notice to GRANTEE for noncompliance with the above conditions or any lawful requirement.

Department of State Lands

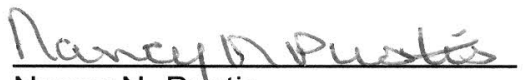

Nancy N. Pustis

Western Region Manager

Land Management Division

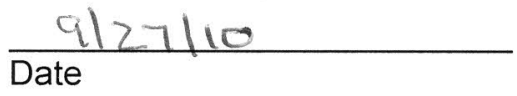




\section{EXHIBIT "A"}

Oregon State University Marine Mammal Institute

Short Term Access Agreement Application

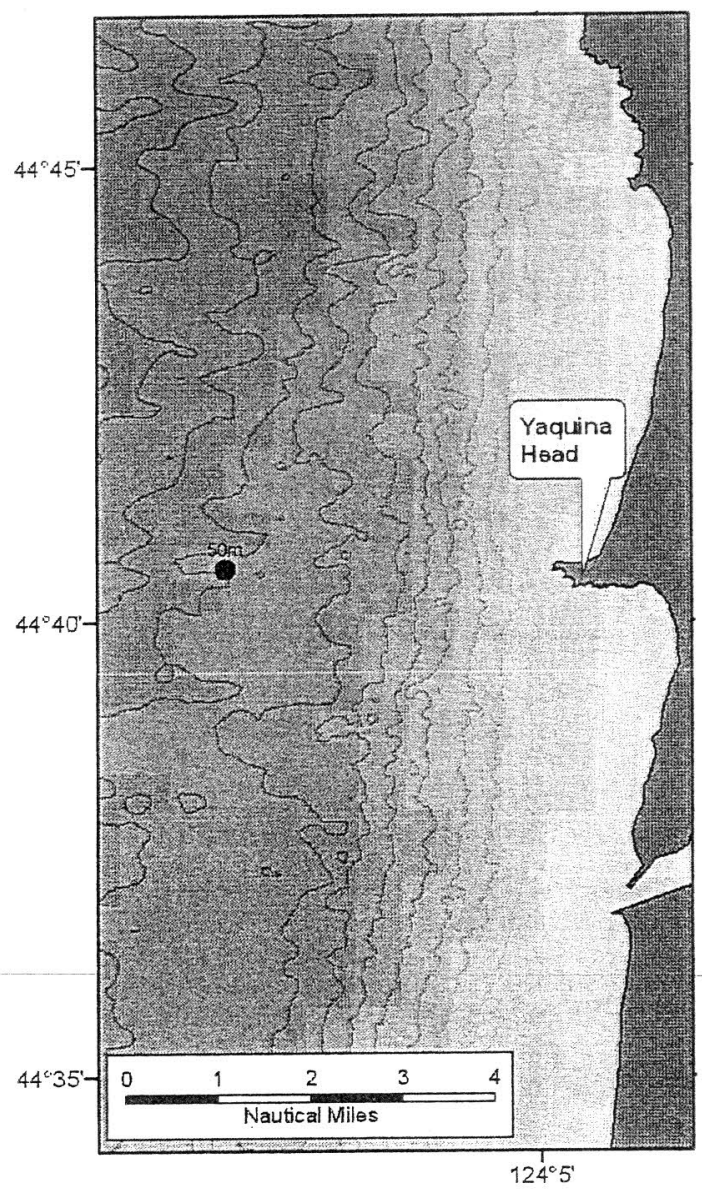

Figure 4: Project location Near Newport, Oregon 


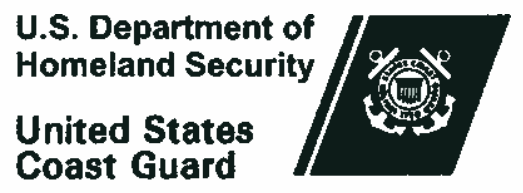

Oregon State University

Marine Mammal Institute

Attn: Ms. Barbara Lagerquist

2030 SE Marine Science Drive

Newport, OR. 97365

Dear Ms. Lagerquist,
Commander

United States Coast Guard

Thirteenth District
915 Second Ave.

Seattle, WA 98174-1067

Staff Symbol: dpw

Phone: (206) 220-7270

Fax: (206) 220-7265

16518

I am writing in reference to an e-mail dated November 10th, 2010 which discusses the placement of a temporary research buoy off of Yaquina Head on the Oregon coast in the following position:

- Yellow Research Buoy

- Marked with yellow retro reflective tape, ownership and phone number.

- Carmanah (601) two nautical mile light.

- FL Y 4s (flashing yellow four seconds, 15 flashes per minute)

- Chart 18561

- $44-40-33.600 \mathrm{~N}, 124-08-24.000 \mathrm{~W}$

I understand that you plan to deploy your buoy during December of 2010 and have it fully removed prior to June of 2011 . I have no objection to this buoy deployment and ask that you be aware of the following:

- Contact my representative listed below immediately upon deploying your buoy to request a Notice to Mariners to advise the boating public that it has been deployed.

- If your buoy is removed prior to June $1 \mathrm{st}, 2011$, I will not require it to be permitted under the Coast Guard Private Aids to Navigation Program.

- Contact my representative listed below if you intend to maintain your buoy past June 1st, 2011, so a Coast Guard Private Aids to Navigation (PATON) application may be drafted for you.

- Any discrepancy in the operation of your buoy (relocated, missing, removed) must be reported immediately to Coast Guard Group North Bend office at (541) 756-9210, 24 hours a day and my representative listed below.

- Contact my representative listed below upon the complete removal of your buoy and all of its associated hardware to request a Notice to Mariners to advise the boating public that your buoy has been removed.

If you have any questions contact my representative, Mr. Timothy Westcott at (206) 220-7285 or at dl3-pf-paton@uscg.mil. Visit our website at: http:/www.uscg.mil/d13/dpw/paton.asp.

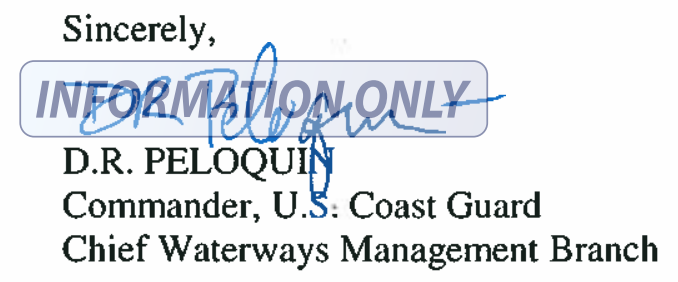

Copy: Commander, Coast Guard Sector Columbia River, Waterways Management Branch Officer in Charge, Aid to Navigation Team Coos Bay 


\section{Commander}

Coast Guard MSU Portland

Waterway Management Branch

6767 North Basin Avenue

Portland, OR 97217

Officer-in-Charge

USCG ANT Coos Bay

P. O. Box 5650

Charleston, OR 97420 